\title{
Fabrication of nano zero valent iron/biopolymer composite with antibacterial properties for simultaneous removal of nitrate and humic acid: Kinetics and isotherm studies
}

\author{
Nazanin Zahra Pourbaghaei \\ Iran University of Science and Technology \\ Mansoor Anbia ( $\nabla$ anbia@iust.ac.ir) \\ Iran University of Science and Technology \\ Fatemeh Rahimi \\ Iran University of Science and Technology
}

\section{Research Article}

Keywords: Simultaneous removal, Nitrate, Humic acid, Antibacterial composite

Posted Date: March 29th, 2021

DOI: https://doi.org/10.21203/rs.3.rs-324935/v1

License: (c) (1) This work is licensed under a Creative Commons Attribution 4.0 International License. Read Full License

Version of Record: A version of this preprint was published at Journal of Polymers and the Environment on July 26th, 2021. See the published version at https://doi.org/10.1007/s10924-021-02209-z. 
Fabrication of nano zero valent iron/biopolymer composite with antibacterial properties for simultaneous removal of nitrate and humic acid: Kinetics and isotherm studies

\author{
Nazanin Zahra Pourbaghaei, Mansoor Anbia*, Fatemeh Rahimi \\ Research Laboratory of Nanoporous Materials, Faculty of Chemistry, Iran University of Science and \\ Technology, Narmak Tehran 16846-13114, Iran
}

*Corresponding Author: anbia@iust.ac.ir; Tel: +98 21 77240516; Fax: +98 2177491204 


\begin{abstract}
This investigation compared the adsorption behavior of humic acid (HA) on cellulose, chitosan and nano zerovalent iron/chitosan (nZVI/chitosan). Results show that nZVI/chitosan is very effective in the adsorption of HA from aqueous media. The feasibility of using nZVI/chitosan as an adsorbent for the simultaneous removal of nitrate and HA from aqueous media was also studied. Structural analyses of the samples were identified by TEM, FT-IR, EDX, XRD and $\mathrm{N}_{2}$ isotherms. The effects of $\mathrm{pH}$, amount of composite, nitrate concentration, HA concentration and contact time and their interactions on responses were explored by central composite design (CCD) and response surface methodology (RSM). The optimal conditions of $\mathrm{pH}$ (5.5), adsorbent amount (0.098 g), reaction time (27 $\mathrm{min})$ and initial concentrations $(110 \mathrm{mg} / \mathrm{L}$ for nitrate and $30 \mathrm{mg} / \mathrm{L}$ for HA) were obtained from desirability function. The adsorption properties of the resulting nanocomposite toward nitrate and HA were investigated through kinetic and isotherm adsorption studies. The adsorption kinetics was found to fit the pseudo-second order model. The results obtained indicate that nitrate uptake fitted well with the Langmuir model while the Freundlich isotherm was the best model for describing the multilayer uptake of HA from aqueous solutions. Moreover, nZVI/chitosan nanocomposite illustrates a very high antibacterial activity against pathogen bacteria strains such as Staphylococcus aureus ATCC 25935, ATCC 25923, and Pseudomonas aeruginosa ATCC 27853. The findings reported in this investigation highlight the potential of using $\mathrm{nZVI} /$ chitosan as a promising adsorbent for the simultaneous removal of nitrate and HA from aqueous solutions.
\end{abstract}

Keywords: Simultaneous removal, Nitrate, Humic acid, Antibacterial composite 


\section{Introduction}

In the process of agricultural and industrial development, environmental and microbial pollution has become the most universal serious problems, so quality and security of drinking water are the tacit requisites for human society [1-3]. An extensive range of environmental pollution such as phenolic compounds, HA, polycyclic aromatic hydrocarbons, nitrate, and heavy metals (lead, arsenic...) in water has become a serious concern for aquatic life and public health. Among them, nitrate and HA are regarded as perilous contaminants in the drinking water [4-8]. Nitrates surely cause harm to the ecosystem and the various aquatic organisms leading to many epidemic diseases including methemoglobinemia, stomach cancer, diabetes, eutrophication, and so on $[4,6,9]$. As a result of the primary problems that increased nitrate concentrations in water makes, the US Environmental Protection Agency (USEPA) has set the maximum contaminant level (MCL) of nitrate to $10 \mathrm{mg} / \mathrm{L}$ in drinking water $[4,5]$.

HA are a sort of macromolecule organic matter that exists in soil and sources of drinking water storage and have a negative surface charge such as carboxylic $(-\mathrm{COOH})$ and phenolic $(-\mathrm{OH})$ which linked with aromatic rings $[7,8,10-12]$. The presence of HA in the water can lead to a yellowish to brown color, taste, and odor problems that are aesthetically unpleasant and can also lead to Blackfoot diseases, cancer, and goiter. Furthermore, HA can be assumed to have effects on disinfection efficiency. It can react with chlorine during water treatment and make strongly carcinogenetic disinfection byproducts (DBPs) such as trihalomethanes [11,13,3]. Therefore, because of the negative effects of HA, the USEPA has established the maximum contaminant level (MCL) for HA in drinking water is $2 \mathrm{mg} / \mathrm{L}$. On the other hand, HA also acts as a layer for bacterial growth in the water distribution system so the microbial pollution is another obstacle caused by pathogenic Gram-negative and positive microorganisms like Staphylococcus aureus (S. aureus), 
Escherichia coli (E. coli) as well as Pseudomonas aeruginosa (P. aeruginosa). Therefore, the removal of nitrate and HA from polluted water is very important to restore water quality [13,3]. Various treatment methods have been applied to remove nitrate and HA from water including coagulation [3,14], ion-exchange [14,15], adsorption [15-17] and membrane technology [16,18]. Most of these methods are not suitable due to the production of secondary waste and high cost [16].

In the past few years, nanoparticles have been used to remove a wide range of pollutants owing to their high adsorption capacity, large surface area, and other physicochemical properties. Nanoparticles such as zero valance iron (nZVI) have potential advantages over existing nanoparticles such as their high removal efficiency as well as their antibacterial properties. Moreover, these nanoparticles have magnetic properties that enable easily and rapidly removes pollutants from water [16,18-20].

According to the scientific literature $[19,20]$ in the process of nitrate removal using nZVI, $\mathrm{Fe}^{0}$ converts nitrate to nitrite, $\mathrm{N}_{2}$, and ammonium [19-22]. Pathways of nitrate reduction by nZVI are demonstrated in Equations 1, 2, and 3.

$\mathrm{NO}_{3}{ }^{-}+4 \mathrm{Fe}^{0}+10 \mathrm{H}^{+} \rightarrow \mathrm{NH}_{4}{ }^{+}+4 \mathrm{Fe}^{2+}+3 \mathrm{H}_{2} \mathrm{O}$

$5 \mathrm{Fe}^{0}+2 \mathrm{NO}_{3}^{-}+12 \mathrm{H}^{+} \rightarrow \mathrm{N}_{2}(\mathrm{~g})+5 \mathrm{Fe}^{2+}+6 \mathrm{H}_{2} \mathrm{O}$

$\mathrm{Fe}^{0}+\mathrm{NO}_{3}^{-}+2 \mathrm{H}^{+} \rightarrow \mathrm{Fe}^{2+}+\mathrm{H}_{2} \mathrm{O}+\mathrm{NO}_{2}^{-}$

However, the bare nZVI tends to accumulate and oxidize, thereby reduces the reactivity surface area, and performance, as a result, causing problems for its use in water treatment. Recently biopolymer-based coatings are one of the most commonly used methods to overcome clumping agglomeration of nanoparticles and to enhance their separation [21]. 
Various biopolymers as iron nanoparticle coatings are used such as starch [22], alginate, cellulose, and chitosan [23,24]. Among these biopolymers, cellulose and chitosan have recently received much attention due to their high uptake performance, excellent biodegradability, good biocompatibility, non-toxicity, low price, high abundance, as well as strong affinity towards certain contaminants to outfit their removal [25-27]. Ahmadi et al. indicated that the coating of nZVI with chitosan resulted in increased stability and adsorption capacity [23]. Furthermore, biopolymers such as cellulose and chitosan are effective adsorbents for nitrate and HA adsorption due to excellent functional groups (hydroxyl and/or amine groups) in their chains $[28,29]$. In fact, these biopolymers have been widely applied both as adsorbents of these contaminants and support for nZVI in treatment processes [30-35]. However, to our knowledge, there are no reports about removing simultaneous HA and nitrate using a low-cost impressive, antibacterial composite system of nZVI/chitosan.

In this current study compared the adsorption behavior of HA on cellulose, chitosan and nZVI/chitosan. Also, magnetic nanocomposite combined the specific surface area of chitosan, the antibacterial capacity of chitosan and nano zero valent iron, and magnetic separation property of nano zero valent iron is synthesized for simultaneous removal nitrate and HA. The surface physicochemical properties and presence of elements and functional groups of the biopolymers and magnetic nanocomposite are explored by different methods. A CCD was chosen to check the effect of five different factors $(\mathrm{pH}$, contact time, composite dose, nitrate concentration, HA concentration) on the simultaneously removal of nitrate and HA by nZVI/chitosan. To achieve the controlling mechanism of the uptake system, the adsorption kinetics and isotherms were assessed. Furthermore, the antibacterial activity of the nZVI/chitosan composites against the E. coli, S. aureus and P. aeruginosa was investigated. Finally, the feasible antibacterial mechanism and 
adsorption isotherms were proposed and reproducibility of the nZVI/chitosan biocomposite under optimal conditions was also assessed.

\section{Materials and methods}

\subsection{Materials}

Chitosan, iron (II) sulfate heptahydrate $\left(\mathrm{FeSO}_{4} \cdot 7 \mathrm{H}_{2} \mathrm{O}\right)$, potassium nitrate $\left(\mathrm{KNO}_{3}\right)$, sodium borohydride $\left(\mathrm{NaBH}_{4}\right)$ and acetic acid were purchased from Sigma-Aldrich. All reagents were analytical grade and were used as received.

\subsection{Preparation of $\mathrm{nZVI} / \mathrm{Chitosan}$ composite}

The nZVI/Chitosan was prepared using a chemical reduction technique (reducing $\mathrm{Fe}^{2+}$ to $\mathrm{Fe}^{0}$ using $\left.\mathrm{NaBH}_{4}\right)[23,36]$. In the beginning, a solution of chitosan $(0.5 \%)$ in $2 \%$ acetic acid was prepared. Due to the negligible solubility of chitosan, the solution was blended for $4 \mathrm{~h}$ with stirring until quite dissolved. In the following, $10 \mathrm{mmol}(2.78 \mathrm{~g})$ of $\mathrm{FeSO}_{4} \cdot 7 \mathrm{H}_{2} \mathrm{O}$ was added to $50 \mathrm{ml}$ of chitosan aqueous solution $(0.5 \%)$ under the $\mathrm{N}_{2}$-purged atmosphere and the solution is stirred rapidly for thirty minutes. Afterward, $50 \mathrm{ml}$ of an aqueous solution containing $30 \mathrm{mmol}(1.14) \mathrm{of} \mathrm{NaBH}_{4}$ in the form of drops was added into the above solution under stirring and nitrogen atmosphere. The chemical reduction reaction is exhibited in Equation (4):

$\mathrm{Fe}^{2+}+2 \mathrm{BH}_{4}^{-}+6 \mathrm{H}_{2} \mathrm{O} \rightarrow \mathrm{Fe}^{0}+2 \mathrm{~B}(\mathrm{OH})_{3}+7 \mathrm{H}_{2}$

After $60 \mathrm{~min}$, the black solid is separated by magnetism. The first is washed with deoxygenated water and then with pure ethanol and acetone, respectively. The nZVI/chitosan was dried under a vacuum situation at $70{ }^{\circ} \mathrm{C}$.

\subsection{Characterization}


FTIR spectra were registered on a Fourier transform infrared spectrometer over the wavenumber range of $4000-400 \mathrm{~cm}^{-1}$ (Shimadzu, 8400S). The core-shell structure of chitosan-nZVI supported was investigated by model transmission electron microscopy (TEM, EM208S, Philips). Furthermore, X-ray energy dispersive spectroscopy was used to analyze the composition of the composite (TESCAN-VEGA III). The crystal structure of cellulose, chitosan and nZVI/chitosan was obtained by X-ray diffraction (XRD, X' per PRO model-Dron-8 diffractometer). According to the $\mathrm{N}_{2}$ adsorption-desorption isotherm (Micromeritics, ASAP 2020), the pore size distribution was achieved by using the Barrett-Joyner-Hallenda $(\mathrm{BJH})$ method and the specific surface area was obtained by using the Brunauer-Emmett-Teller (BET) method. The magnetic property of nZVI/chitosan was distinguished using Vibrating Sample Magnetometer (VSM, 7400, Lakeshore). The concentration of nitrate in a solution containing natural organic matter samples was colorimetrically determined by using a UV-Vis spectrophotometric in which nitrate was analyzed using the Vanadium reduction method at $540 \mathrm{~nm}$ [37]. Moreover, the concentration of HA was obtained via a UV-Vis spectrophotometer at $420 \mathrm{~nm}$ [32].

\subsection{Antibacterial Testing}

The antimicrobial activities of the chitosan and nZVI/chitosan were determined using the $1.5 \times 10^{8}$ colony-forming units (CFU)/ml of E. coli and S. aureus in an agar medium. Then, a disc with a 1 $\mathrm{cm}$ diameter of chitosan and $\mathrm{nZVI} /$ chitosan $(0.08 \mathrm{~g})$ was placed in the culture medium containing the bacteria. The media containing bacteria and disc was located at $4{ }^{\circ} \mathrm{C}$ for $2 \mathrm{~h}$ to complete diffusion of the disc. Followed by the culture mediums were incubated at $37^{\circ} \mathrm{C}$ for 24 hours.

\subsection{Analytical Methods}

To investigate the simultaneous removal of HA and nitrate by nZVI/chitosan, a binary nitrate-HA system was used in the experiments. Therefore, the stock solutions of the nitrate and HA were 
prepared by the dissolution of analytical-grade $\mathrm{KNO}_{3}$ and $\mathrm{HA}$ in distilled water, respectively. All experiments were carried out at various conditions, according to the designed experiments, in a 50 $\mathrm{ml}$ flask on a shaker $(150 \mathrm{rpm})$ to find the optimum initial nitrate and HA concentrations, composite dose, contact time, and $\mathrm{pH}$. Furthermore, all $\mathrm{pHs}$ were adjusted with Britton-Robinson (BR) buffer solution. CCD experiments surveyed and appraised the effect of individual variables as well as their conceivable interactions on the removal percentage of nitrate and HA as responses. The equilibrated samples were taken out and the concentration of nitrate and HA in the solution was checked simultaneously by UV-Vis spectrophotometer. Moreover, for co-adsorption in binary systems, the procedures for the study of isotherms were also performed under optimum conditions. The removal percentage and adsorption capacity of nitrate and HA were determined with the Equations (5) and (6), respectively [38].

$\mathrm{R} \%=\frac{\left(\mathrm{C}_{0}-\mathrm{C}_{\mathrm{e}}\right)}{\mathrm{C}_{0}} 100$

$\mathrm{q}_{\mathrm{e}}=\frac{\left(\mathrm{C}_{0}-\mathrm{C}_{\mathrm{e}}\right) \mathrm{V}}{\mathrm{w}}$

Where $\mathrm{C}_{0}(\mathrm{mg} / \mathrm{L})$ and $\mathrm{C}_{\mathrm{e}}(\mathrm{mg} / \mathrm{L})$ are the initial and final concentrations of concentration (i.e., HA and nitrate) in the aqueous solution. $\mathrm{q}_{\mathrm{e}}(\mathrm{mg} / \mathrm{g})$ is the equilibrium amount of nitrate and HA adsorbed per unit mass of adsorbent, $\mathrm{m}(\mathrm{g})$ is the dose of adsorbent and $\mathrm{V}(\mathrm{L})$ is the volume of nitrate and HA solution.

\subsection{Experimental Design}

RSM consists of a group of statistical and mathematical techniques that are effective in developing, improving, and optimizing a process. CCD is the most popular RSM and it find outs to optimize the effective experimental variables with a minimum number of experimental runs, in addition to analyzing the interaction between variables [39-43]. 
In this study, a CCD was used for RSM to obtain the emphasis of the influences of the variables (i.e., nitrate concentration, HA concentration, $\mathrm{pH}$, contact time, composite dose) on the responses (i.e., the percentage removal of nitrate and $\mathrm{HA}$ ) by $\mathrm{nZVI/chitosan.}$

Five numerical factors were studied in five levels including two levels for axial point $(+/-\alpha)$, two levels for high/low levels $(+/-1)$, and one level for the center point. Six replicates were made for center point and 21 for not center, which made a CCD with overall 27 experimental runs. These five variables together with their respective ranges were chosen based on the literature and our preliminary studies. The experimental data were analyzed and validated for the removal percentage of nitrate and $\mathrm{HA}$ on the $\mathrm{nZVI} /$ chitosan, and each response was correlated with the most suitable model developed from the quadratic model (Equation 6):

$\mathrm{Y}=\mathrm{b}_{0}+\sum \mathrm{b}_{\mathrm{i}} \mathrm{Xi}_{\mathrm{i}}+\sum \mathrm{b}_{\mathrm{ii}} \mathrm{Xi}^{2}+\sum \sum \mathrm{b}_{\mathrm{ij}} \mathrm{X}_{\mathrm{ij}} \mathrm{X}_{\mathrm{j}}$

Where $\mathrm{Y}$ is the predicted response (removal percentage of either HA and nitrate), xi's are the input variables that are studied for every experimental run. The parameters $b_{0}$ is the model constant, $b_{i}$ $(\mathrm{i}=1,2, \ldots, \mathrm{n})$ is the linear coefficient, $\mathrm{b}_{\mathrm{ii}}(\mathrm{i}=1,2, \ldots, \mathrm{n})$ is the quadratic, $\mathrm{b}_{\mathrm{ij}}(\mathrm{i}=1,2, \ldots, \mathrm{n}, \mathrm{j}=1,2$, $\ldots, \mathrm{n})$ is interaction coefficient. Design Expert 11.0.3.0 software was applied for the actuarial analysis of results attained from the experimental design.

\section{Result and Discussion}

\subsection{Physicochemical characterization of adsorbents}

FTIR measurements were carried out to illuminate the stabilization mechanism and gain better insight into the interactions between the different functional groups of chitosan and the nZVI particles. Fig. 1 showed the FT-IR spectra of cellulose, chitosan and nZVI/chitosan. In the cellulose ((Fig. 1 (a)), the absorption band at $1650 \mathrm{~cm}^{-1}$ is associated with $-\mathrm{OH}$ bending of the adsorbed water. The band at $1160 \mathrm{~cm}^{-1}$ was attributed to C-O stretching in acetyl group. The 
characteristic band was located at $1055 \mathrm{~cm}^{-1}$, assigned to the pyranose ring skeletal vibration of the $\mathrm{C}-\mathrm{O}-\mathrm{C}$.

The principal bonds in the IR spectra of chitosan (Fig. 1 (b)) can be seen as follows [44]: a broad and strong overlapped band at around $3446 \mathrm{~cm}^{-1}\left(\mathrm{O}-\mathrm{H}\right.$ and $\mathrm{N}-\mathrm{H}$ stretch); a weak band at $2873 \mathrm{~cm}^{-}$ ${ }^{1}$ (C-H stretch), $1645 \mathrm{~cm}^{-1}\left(\mathrm{~N}-\mathrm{H}\right.$ bending vibration), $1386 \mathrm{~cm}^{-1}$ (-C-O stretching of the primary alcoholic group), $1083 \mathrm{~cm}^{-1}$ (C-O stretching vibrations) [45,46,36,47]. According to Liang's studies [48], the adsorption of chitosan molecules on the surfaces of iron nanoparticles causes considerable changes in the tensile frequency of the chitosan functional groups.

It can be seen from the Fig. 1 (c) that several remarkable changes have occurred in the composite spectrum compared to the chitosan spectrum, which may confirm the accuracy of the composite synthesis. The stretching bands of the hydroxyl and amino groups shift from $3446 \mathrm{~cm}^{-1}$ to 3426 $\mathrm{cm}^{-1}$ for $\mathrm{nZVI} /$ chitosan that showing the $\mathrm{N}-\mathrm{H}$ and $\mathrm{O}-\mathrm{H}$ vibration was affected because of the iron attachment. Moreover, the N-H bending vibration shifts from $1645 \mathrm{~cm}^{-1}$ to $1627 \mathrm{~cm}^{-1}$ and accompanied by a decrease in intensity. The position of C-O peaks shift from 1386 and $1083 \mathrm{~cm}^{-}$ ${ }^{1}$ to 1300 and $1056 \mathrm{~cm}^{-1}$ in the composite, respectively [49]. On the other hand, the peak at around $613 \mathrm{~cm}^{-1}$ in the $\mathrm{nZVI} /$ chitosan, was attributed to the Fe-O stretching vibration implying that the nano zero-valent iron was successfully prepared and introduced into the chitosan [23].

\section{Insert here Figure 1}

The $\mathrm{N}_{2}$ isotherms of cellulose, chitosan and nZVI/chitosan are demonstrated in Fig. 2. The BET specific surface area for cellulose was equal to $0.85 \mathrm{~m}^{2} / \mathrm{g}$ and the average pore diameter was 89.16 $\mathrm{nm}$. The BET surface areas of chitosan and nZVI/chitosan were found to be 0.97 and $63 \mathrm{~m}^{2} / \mathrm{g}$, respectively. The average pore diameters of chitosan and nZVI/chitosan were found to be 90.22 and $13.29 \mathrm{~nm}$, respectively. It was obvious that the surface areas of chitosan increased when it was 
coated on the nZVI. The BET surface area of the nZVI/chitosan was greater than that of chitosan, most likely due to the fact that the nanoparticles of nZVI, which had high surface area.

\section{Insert here Figure 2}

The XRD spectra of samples in the $2 \theta$ range of $5-70^{\circ}$ are shown in Fig. 3. Three major peaks in the XRD pattern of cellulose were observed at $2 \theta=15^{\circ}, 24^{\circ}$ and $35^{\circ}$, reflecting the low degree of crystallinity of cellulose. Fig. 3 (b) shows the XRD data of the chitosan. It is apparent from the XRD results that chitosan displays typical peaks at $2 \theta=11^{\circ}$ and $23^{\circ}$. As shown in Fig. 3 (c), $\mathrm{nZVI} / \mathrm{chitosan}$ indicates the main peaks at the $2 \theta$ of $46.7^{\circ}$ and $66.25^{\circ}$ due to the presence of metallic $\mathrm{Fe}[23,36,50]$.

\section{Insert here Figure 3}

The elemental composition of cellulose, chitosan and nZVI/chitosan were evaluated from EDX spectrum analysis and results were depicts in Fig. 4. The EDX spectrums displayed the presence

of $\mathrm{C}$ and $\mathrm{O}$ in the cellulose and the presence of $\mathrm{C}, \mathrm{O}$, and $\mathrm{N}$ in the chitosan. The spectrum of nZVI/chitosan in Fig. 4 illustrates peaks of $\mathrm{C}, \mathrm{O}$, and $\mathrm{N}$ in addition to Fe which is the result of successful modification of Fe nanoparticles. In addition, the EDX elemental mapping image of synthesized nanocomposite reveal that Fe species are incorporated uniformly in the synthesized nZVI/chitosan.

\section{Insert here Figure 4}

TEM analysis was performed to accurately investigate morphology. Fig. 5 illustrates that almost spherical Fe nanoparticles are formed inside the chitosan templates and the nZVI because of the presence of chitosan are well diffused. Furthermore, the core-shell structure of the composite is well indicated, the chitosan polymer layer being the clear space as the shell and the dark space corresponding to the iron nanoparticles as the core [45]. 


\section{Insert here Figure 5}

A magnetic hysteresis curve of nZVI/chitosan composite at room temperature and in the fields from $-10,000$ to 10,000 Oersted is shown in Fig. 6. The saturation magnetization (Ms) of $\mathrm{nZVI} /$ chitosan was found to be $35.11 \mathrm{emu} / \mathrm{g}$. As it is seen, the $\mathrm{nZVI} / \mathrm{chitosan}$ displays superparamagnetic characteristic behavior at room temperature. When an outer magnetic field was placed under the aqueous solution including the nZVI/chitosan composite, the substance can be quickly attracted and separated from the solution, therefore preventing environmental pollution. Similar results for the superparamagnetic behavior of nZVI were reported in the literature [15]. The above results show that zero valent iron nanoparticles have been successfully loaded onto chitosan and the nZVI/chitosan composite could provide a high surface area and accessible for simultaneous removal of nitrate and HA. Furthermore, nZVI/chitosan could be applied as a magnetic composite to remove contaminants from an aqueous solution leading to preventing secondary pollution.

\section{Insert here Figure 6}

\subsection{Study on HA adsorption by adsorbents}

The adsorption isotherms of HA adsorption on the cellulose, chitosan and nZVI/chitosan are displayed in Fig. 10. These adsorbents all demonstrated enhanced HA uptake with the increase of initial concentrations of HA solutions and gradually reached saturation. It is clear from the Fig. 10 that the chitosan possessed a higher adsorption performance than that of the cellulose. The possible adsorption mechanisms of HA on chitosan involved different kinds of interactions. The adsorption

process involved electrostatic attraction between the $\mathrm{RCOO}^{-}$groups of $\mathrm{HA}$ and $\mathrm{NH}_{3}^{+}$groups of chitosan. Other mechanisms such surface adsorption and van der Waals interaction also played a key role during the adsorption process. The nZVI/chitosan displays much further HA uptake than 
the pristine chitosan. Composition of chitosan by the nZVI increased the specific surface area, which facilitated fast mass transfer of HA inside the nZVI/chitosan structure and improved the contact between HA and binding sites. The nZVI/chitosan was used as suitable adsorbent for the further investigation.

\section{Insert here Figure 10}

\subsection{RSM Model Fitting}

The experimental results nitrate and HA removal percentage with independent variables $[\mathrm{A}=\mathrm{pH}$, $\mathrm{B}=$ contact time, $\mathrm{C}=$ nitrate concentration, $\mathrm{D}=\mathrm{HA}$ concentration, $\mathrm{E}=$ nanocomposite dose $]$ were established in Table 2.

\section{Insert here Table 2}

The results were collected using the standard polynomial regression method and make it conceivable to obtain the following Equations (7 and 8) for nitrate and HA, respectively:

$\mathrm{R}_{1}=85.03-3.43 \mathrm{~A}-0.4250 \mathrm{~B}-1.22 \mathrm{C}-2.50 \mathrm{D}+1.12 \mathrm{E}-1.20 \mathrm{AB}+1.02 \mathrm{AC}-1.28 \mathrm{AD}-$

$1.98 \mathrm{AE}+1.17 \mathrm{BC}+0.6996 \mathrm{BD}-2.05 \mathrm{BE}+1.10 \mathrm{CD}-1.28 \mathrm{CE}-0.4254 \mathrm{DE}-0.2766 \mathrm{~A}^{2}-1.45$

$B^{2}-0.7766 C^{2}-0.1391 D^{2}-0.3016 E^{2}$

$\mathrm{R}_{2}=96.06+3.75 \mathrm{~A}+0.6750 \mathrm{~B}+0.8750 \mathrm{C}-1.00 \mathrm{D}+1.77 \mathrm{E}-3.00 \mathrm{AB}-1.85 \mathrm{AC}-1.50 \mathrm{AD}-$

3.12 $\mathrm{AE}+2.58 \mathrm{BC}+3.28 \mathrm{BD}+1.90 \mathrm{BE}+2.63 \mathrm{CD}+1.75 \mathrm{CE}+3.28 \mathrm{DE}-2.74 \mathrm{~A}^{2}+0.2518 \mathrm{~B}^{2}$ $+0.3268 C^{2}+0.3893 D^{2}+0.0018 E^{2}$

Tables 3 and 4 show the results of the analysis of variance (ANOVA) of nitrate and HA, respectively. According to the results of the ANOVA test for response nitrate removal efficiency has indicated that the model was of great significance $(\mathrm{F}$ value $=3444.28, \mathrm{P}$-value $<0.0001)$. The adaptability of the multinomial model equation for nitrate ions fitting was declared the coefficient 
of designation predicted $R^{2}=0.9728$ and adjusted $R^{2}=0.9996$. The high adjusted $R^{2}$ values display good communication between the obtained model and the experimental datum.

Insert here Table 3 and Table 4

ANOVA data of HA (Table 4) indicates p-value $<0.0001$ and F values 87.88 that establish the high yield and suitability of the model for appropriate and interpretation of empirical data, while the coefficients of definition for its multinomial model equation are predicted $R^{2}=0.8426$ and adjusted $\mathrm{R}^{2}=0.9858$.

\subsection{Investigation of interaction of parameters with 3D graphs}

Fig. 11 (a-f) displays the simultaneous effect of different parameters on the percentage removal of nitrate and HA.

\section{Insert here Figure 11}

As shown in (Fig. 11 (a) ), the percentage removal of nitrate in solution decreased with increasing $\mathrm{pH}$ from 3 to 8 and enhanced with the amount of composite from 0.05 to $0.1 \mathrm{~g}$. The enhancement of nitrate removal in acidic $\mathrm{pH}$ could be due to the following reasons:

1) Acidic condition helps to eliminate the iron oxide formed in the surface during nZVI oxidation and constantly makes the fresh surface of composite exposed to the solution [61].

2) Acidic solution is favorable for nZVI corrosion, so the oxidation process of zero-valent iron is dramatically increased and the electrons more readily available for nitrate reduction $[61,62]$.

3) Hydroxyl and amine functional groups on the chitosan surface are positively charged in acidic conditions and can adsorb nitrate ions and reduce their concentration [63].

Fig. 11 (b) demonstrates that the percentage removal of HA increased to $\mathrm{pH}$ about 7 after that it is almost constant, while the dose of composite in ranging from 0.05 to $0.1 \mathrm{~g}$. Generally, adsorption 
behavior of HA on the nZVI/chitosan depends on the surface charge of HA and the nZVI/chitosan at different pHs. The $\mathrm{pH}_{\mathrm{pzc}}$ of the $\mathrm{nZVI} /$ chitosan and $\mathrm{HA}$ are 7.83 and 1.6, respectively. Accordingly, HA removal could occur through two processes:

1) At pHs less than 7.83 , the surface of the $\mathrm{nZVI} /$ chitosan is positively charged and the adsorption of HA occurs mainly via electrostatic interaction.

2) At grater $\mathrm{pH}$ than 7.83, due to the negative surface charge of the composite, the electrostatic adsorption was very limited and adsorption occurs through complex formation between phenolic and carboxyl groups of HA and iron oxide on surface nZVI [62,64], as shown in the following:

$\mathrm{Fe}-\mathrm{OH}+\mathrm{R}-\mathrm{COO}-\rightarrow \mathrm{Fe}-\mathrm{OCC}-\mathrm{R}+\mathrm{OH}^{-}$

To better investigate the interaction between $\mathrm{HA}$ and $\mathrm{nZVI} /$ chitosan in the presence and absence of nitrate, FT-IR spectra of the composite after reaction with HA and the HA /nitrate binary system were studied under acid conditions (Fig. 12). The FTIR spectra of HA has been reported by the previous literature [65]. Fig. 12 (a) illustrates the FTIR spectrum of nZVI/chitosan after adsorption of HA. Based on the observations, the C-O peak at $1056 \mathrm{~cm}^{-1}$ shifted to $1040 \mathrm{~cm}^{-1}$ compared to the HA. Furthermore, the displacement of the N-H peak from 1627 to $1600 \mathrm{~cm}^{-1}$ and the change in its intensity can indicate electrostatic interaction. These findings suggested that carboxylic or phenolic functional groups of HA might be attracted through electrostatic by the surface of composite or be complexed with iron oxides. Fig. 12 (b) indicates the IR spectra of the composite after simultaneous reaction with nitrate and HA. By comparing the two spectra (Fig. 12 (a and b)), it can be seen that the presence of nitrate reduced the rate of HA removal in acidic conditions due to competition between two contaminations for the adsorption on composite active sites.

\section{Insert here Figure 12}


Fig. 11 ( $\mathrm{c}$ and d) presents the percentage removal of nitrate and HA increased with increasing the dose of composite from 0.05 to $0.1 \mathrm{~g}$ and with reaction time ranging from 25 to $60 \mathrm{~min}$. In general, with increasing the dose of $\mathrm{nZVI} /$ chitosan, the number of active sites for reaction increases, resulting in higher removal efficiency. Moreover, because of the high kinetics of the reaction, the contact time did not have much effect.

Fig. 11 (e and $\mathrm{f}$ ) displays the percentage of nitrate and HA removal by nZVI/chitosan as a function of the concentration of these two pollutants in the binary system. As shown in Fig. 11 (e) with increasing the concentration of HA, the percentage of nitrate removal is reduced owing to the accumulation of iron oxides-HA complexes formed on the nZVI/chitosan surface that prevents the nitrate mass transfer [64]. On the other hand, Fig. 11 (f) depicts that with an enhancement of the nitrate concentration, because of the enhancement possibility of iron oxides-HA complexes formation, the percentage of HA removal increases [62,64].

\subsection{Response optimization}

The process variables were optimized to obtain the maximum removal percentage of nitrate and HA simultaneously by nZVI/chitosan with a quadratic model in the empirical range studied. The optimal conditions were obtained to be $\mathrm{pH} 5.5,0.098 \mathrm{~g}$ composite dose, and 27 min contact time that give maximum nitrate and HA removal percentage of $90.0 \%$ and $98.1 \%$, respectively. The optimum removal conditions were checked experimentally by running four experiments under equal conditions. The results displayed an average HA and nitrate adsorption efficiency of $97.3 \% \pm 1.2$ and $89.3 \% \pm 1.4$, respectively which support the adequacy of CCD optimization of the influences of the various experimental factors.

\subsection{Antibacterial activity of nZVI/chitosan composite}


Antibacterial properties of chitosan and nZVI/chitosan composite against five bacterial species: strains Gram-negative (E. coli ATCC 25922, E. coli1 ATCC 1330 and P. aeruginosa 27853), Gram-positive (S. aureus2 ATCC 25923 and S. aureus1 ATCC 25935) by the presence or absence of inhibition zone diameters were examined.

From Table 1, it is clear that pure chitosan did not show antibacterial activity against Bactria. However, as shown in Fig. 7, the nZVI/chitosan showed excellent antibacterial activity against Gram-positive bacteria (S. aureus2 ATCC 25923 and S. aureus1 ATCC 25935), with a very explicit inhibition zone of almost $29 \mathrm{~mm}$ (Fig. 8).

\section{Insert here Table 1 \\ Insert here Figure 7 \\ Insert here Figure 8}

According to the previous reports, the properties of antibacterial chitosan depended on the molecular weight and solubility in water [51,52]. Chitosan alone has weak antibacterial properties, so the addition of certain metals such as iron improves the antibacterial properties of chitosan [5355]. Therefore, this antimicrobial activity of $\mathrm{nZVI} /$ chitosan is effectively relevant to the presence of loaded nano zero-valent iron nanoparticles. Three possible mechanisms have been suggested for the nZVI/chitosan based on the release of iron ions from the composite (Fig. 9). In the first mechanism, iron can be adsorbed by the electronegative molecules of the bacterial wall, resulting in bacterial destruction [56]. The second mechanism is based on oxidative stress generated by reactive oxidative species (ROS) [57]. The reaction of zero-valent iron nanoparticles with intracellular oxygen leads to ROS generation and eventually disrupting cell membranes [57-59]. The third mechanism involves the passage of iron ions through the bacterial cell and interaction 
with DNA $[56,60]$. Accordingly, our findings illustrate that nZVI/chitosan indicated antibacterial properties which would kill the harmful bacteria present in contaminated water.

\section{Insert here Figure 9}

\subsection{Adsorption kinetics}

The adsorption rate is a vital parameter to assess the efficiency of an adsorbent for the removal of contaminates. The adsorption of nitrate and HA onto the nZVI/chitosan was explained through intraparticle diffusion, pseudo-first-order and pseudo-second-order kinetic models. The linearized forms of mentioned models are as follows, respectively [66,67]:

$\mathrm{q}=\mathrm{K}_{\mathrm{i}} \mathrm{t}^{1 / 2}+\mathrm{C}$

$\log \left(q_{e}-q_{t}\right)=\log q_{e}-\left(\frac{K_{1}}{2.303}\right) t$

$\frac{\mathrm{t}}{\mathrm{q}_{\mathrm{t}}}=\frac{1}{\mathrm{~K}_{2} \mathrm{q}_{\mathrm{e}}^{2}}+\left(\frac{1}{\mathrm{q}_{\mathrm{e}}}\right) \mathrm{t}$

Where $\mathrm{K}_{\mathrm{i}}\left(\mathrm{g} / \mathrm{mg} \min ^{0.5}\right), \mathrm{K}_{1}(\mathrm{~L} / \mathrm{min})$ and $\mathrm{K}_{2}(\mathrm{~g} / \mathrm{mg} \min )$ are the rate constants of intraparticle diffusion, pseudo-first and pseudo-second order models, respectively; $\mathrm{qt}_{\mathrm{t}}(\mathrm{mg} / \mathrm{g})$ is the time dependent amount of nitrate and HA adsorbed per unit mass of nZVI/chitosan.

The obtained parameters with correlation coefficients $\left(\mathrm{R}^{2}\right)$ of three kinetic models are given in Table 5. The pseudo-second-order model seemed to describe the kinetic data better as compared with the intraparticle diffusion and pseudo-first-order models for fitting the kinetic data of nitrate and HA uptake, which implied that the nitrate and HA removal are a chemical adsorption process.

\subsection{Adsorption isotherms}

Insert here Table 5 
Adsorption isotherms illustrate the correlation between the adsorbent and adsorbates, which is decisive for optimizing the adsorption procedure [16]. In order to attain the uptake performance of nZVI/chitosan for nitrate and HA in adsorption systems, Langmuir, Freundlich, and Temkin isotherm models were employed in this work [18]. The linear forms of the Langmuir, Freundlich, and Temkin isotherms are illustrated by the following Equations, respectively. [19-21,16].

$\frac{\mathrm{C}_{\mathrm{e}}}{\mathrm{q}_{\mathrm{e}}}=\frac{1}{\mathrm{~K}_{\mathrm{L}} \mathrm{q}_{\mathrm{m}}}+\frac{1}{\mathrm{q}_{\mathrm{m}}} \mathrm{C}_{\mathrm{e}}\left[\mathrm{R}_{\mathrm{L}}=\frac{1}{1+\mathrm{K}_{\mathrm{L}} \mathrm{C}_{0}}\right]$

$\ln q_{e}=\ln K_{F}+\left(\frac{1}{n}\right) \ln C_{e}$

$\mathrm{q}_{\mathrm{e}}=\mathrm{B}_{\mathrm{T}} \ln \mathrm{A}_{\mathrm{T}}+\mathrm{B}_{\mathrm{T}} \ln \mathrm{C}_{\mathrm{e}}$

Where $\mathrm{q}_{\mathrm{m}}(\mathrm{mg} / \mathrm{g})$ and $\mathrm{K}_{\mathrm{L}}(\mathrm{L} / \mathrm{mg})$ are the maximum monolayer adsorption capacity and Langmuir constant, respectively; $\mathrm{R}_{\mathrm{L}}$ is the separation factor; $\mathrm{n}$ and $\mathrm{K}_{\mathrm{F}}(\mathrm{L} / \mathrm{g})$ are constants representing the heterogeneity factor and the adsorbent capacity, respectively; $\mathrm{B}_{\mathrm{T}}$ and $\mathrm{A}_{\mathrm{T}}$ are the Temkin constant, respectively. The results of adsorption isotherm for nitrate and HA in aqueous systems are shown in Table 6 . It can be observed from Table 6 that $\mathrm{R}^{2}$ obtained from the Langmuir model was greater than the Temkin and Freundlich models for nitrate in aqueous systems. According to the results, nitrate uptake on $\mathrm{nZVI} /$ chitosan mainly took place in a monolayer uptake pattern. As for HA, the high value of $\mathrm{R}^{2}$ supports the best and successful applicability of Freundlich isotherm for fitting equilibrium data related to $\mathrm{HA}$ adsorption onto nZVI/chitosan. The result suggested a heterogeneous distribution of adsorption sites on the nZVI/chitosan surface. The heterogeneity was caused by the attendance of numerous functional groups (derived from HA) on the adsorbent surface, and also by the diverse mechanism of liquid-solid interaction. As a result, it allowed multilayer uptake of HA.

The obtained $\mathrm{R}_{\mathrm{L}}$ values were between 0 and 1 that illustrates desirable adsorption. Furthermore, the magnitude of $1 / \mathrm{n}$ in the Freundlich model is a measure of adsorption intensity, displays 
desirable adsorption when $1 / \mathrm{n}$ is $<1$. Both of the $1 / \mathrm{n}$ values were $<1$ for nitrate and $\mathrm{HA}$ in the adsorption system, indicating a beneficially uptake for nitrate and HA on nZVI/chitosan.

\section{Insert here Table 6}

\section{Conclusions}

In summary, here we present for the first time, nZVI/chitosan composite as an antibacterial adsorbent for simultaneous removal of nitrate and HA. The synthesized composite has a core-shell structure with high surface area and inhibition of growth S. aureus ATCC 25935, ATCC 25923, and P. aeruginosa ATCC 27853. Besides, the VSM result indicated that the nZVI/chitosan is easily collected by the magnetic field and separates the contaminants from the aqueous media. CCD was utilized to identify the optimal conditions of the simultaneous removal process and obtain maximum efficiency. To achieve maximum removal percentage $(90.0 \%$ for nitrate and $98.1 \%$ for HA mg/L), from process optimization modeling the optimum reaction time, adsorbent amount, $\mathrm{pH}$, initial nitrate concentration, and initial HA concentration were found to be $27 \mathrm{~min}, 0.098 \mathrm{~g}$, $5.5,110 \mathrm{mg} / \mathrm{L}$, and $30 \mathrm{mg} / \mathrm{L}$ respectively. On the basis of kinetic studies, the pseudo-second-order model could describe the nitrate and HA uptakes on nZVI/chitosan well, which refers to the chemisorption mechanism. The isotherm equilibrium data fitted well with Langmuir and Freundlich models for nitrate and HA uptake, respectively. Consequently, our laboratory studies suggest that this antibacterial composite with fast separation has great potential for the simultaneous removal of nitrate and HA.

\section{Acknowledgements}

The authors are thankful to the Research Council of Iran University of Science and Technology (Tehran) for financial support to this study. 


\section{Compliance with Ethical Standards}

Conflict of Interest The authors declare no competing financial interest. 


\section{References}

1. Chen L, Yu H, Deutschman C, Yang T, Tam KC (2020) Novel design of Fe-Cu alloy coated cellulose nanocrystals with strong antibacterial ability and efficient $\mathrm{Pb}^{2+}$ removal. Carbohydrate Polymers 234:115889

2. Ni Z, Wang Z, Sun L, Li B, Zhao Y (2014) Synthesis of poly acrylic acid modified silver nanoparticles and their antimicrobial activities. Materials Science and Engineering: C 41:249-254

3. Mohamed RR, Elella MHA, Sabaa MW (2017) Cytotoxicity and metal ions removal using antibacterial biodegradable hydrogels based on $\mathrm{N}$-quaternized chitosan/poly (acrylic acid). International journal of biological macromolecules 98:302-313

4. Esmaeili Bidhendi M, Asadi Z, Bozorgian A, Shahhoseini A, Gabris MA, Shahabuddin S, Khanam R, Saidur R (2020) New magnetic $\mathrm{Co}_{3} \mathrm{O}_{4} / \mathrm{Fe}_{3} \mathrm{O}_{4}$ doped polyaniline nanocomposite for the effective and rapid removal of nitrate ions from ground water samples. Environmental Progress \& Sustainable Energy 39:13306

5. Kamarehie B, Aghaalib E, Musavic S, Hashemid S, Jafaria A (2018) Nitrate removal from aqueous solutions using granular activated carbon modified with iron nanoparticles. atmosphere 1:4

6. Liu X, Huang M, Bao S, Tang W, Fang T (2020) Nitrate removal from low carbon-to-nitrogen ratio wastewater by combining iron-based chemical reduction and autotrophic denitrification. Bioresource Technology 301:122731

7. Li S, Yang Y, Huang S, He Z, Li C, Li D, Ke B, Lai C, Peng Q (2020) Adsorption of humic acid from aqueous solution by magnetic Zn/Al calcined layered double hydroxides. Applied Clay Science $188: 105414$

8. Pormazar SM, Ehrampoush MH, Dalvand A (2020) Removal of humic acid from aqueous solution by $\mathrm{Fe}_{3} \mathrm{O}_{4} @$ L-arginine magnetic nanoparticle: kinetic and equilibrium studies. International Journal of Environmental Analytical Chemistry:1-16 
9. Rajeswari A, Amalraj A, Pius AJJoWPE (2016) Adsorption studies for the removal of nitrate using chitosan/PEG and chitosan/PVA polymer composites. Journal of Water Process Engineering 9:123-134

10. Naghizadeh M, Taher MA, Tamaddon A-M (2020) Application of $\mathrm{CoFe}_{2} \mathrm{O}_{4} @ \mathrm{SiO}{ }_{2} @$ Chitosan Nanoparticles for Cadmium (II) Preconcentration in Totally Different Samples and its Determination through ETAAS. Silicon:1-12

11. Alizadeh S, Sadeghi H, Vosoughi M, Dargahi A, Mokhtari SA (2020) Removal of humic acid from aqueous media using Sono-Persulphate process: optimization and modelling with response surface methodology (RSM). International Journal of Environmental Analytical Chemistry 2:1-15

12. Beiki S, Moniri E, Hassani AH, Ahmad Panahi H (2020) Preparation and Characterization of Dendrimer-Modified Magnetite Nanoparticles for Adsorption of Humic Acid from Aqueous Solution. ChemistrySelect 5:7197-7204

13. Kumari M, Gupta SK (2020) A novel process of adsorption cum enhanced coagulation-flocculation spiked with magnetic nanoadsorbents for the removal of aromatic and hydrophobic fraction of natural organic matter along with turbidity from drinking water. Journal of Cleaner Production 244:118899

14. Ma S, Zhan S, Jia Y, Zhou Q (2015) Highly efficient antibacterial and Pb (II) removal effects of Ag$\mathrm{CoFe}_{2} \mathrm{O}_{4}$-GO nanocomposite. ACS applied materials \& interfaces 7:10576-10586

15. Wang J, Zhang W, Kang X, Zhang C (2019) Rapid and efficient recovery of silver with nanoscale zerovalent iron supported on high performance activated carbon derived from straw biomass. Environmental Pollution 255:113043

16. Tran TH, Le AH, Pham TH, Nguyen DT, Chang SW, Chung WJ, Nguyen DD (2020) Adsorption isotherms and kinetic modeling of methylene blue dye onto a carbonaceous hydrochar adsorbent derived from coffee husk waste. Science of The Total Environment 725:138325

17. Salehi S, Anbia MJJoI, Polymers O, Materials (2017) Adsorption Selectivity of $\mathrm{CO}_{2}$ and $\mathrm{CH}_{4}$ on Novel PANI/Alkali-Exchanged FAU Zeolite Nanocomposites. Journal of Inorganic and Organometallic Polymers and Materials 27:1281-1291 
18. Wei W, Han X, Zhang M, Zhang Y, Zheng C (2020) Macromolecular humic acid modified nanohydroxyapatite for simultaneous removal of $\mathrm{Cu}$ (II) and methylene blue from aqueous solution: Experimental design and adsorption study. International Journal of Biological Macromolecules 150:849-860

19. Ghaedi AM, Karamipour S, Vafaei A, Baneshi MM, Kiarostami V (2019) Optimization and modeling of simultaneous ultrasound-assisted adsorption of ternary dyes using copper oxide nanoparticles immobilized on activated carbon using response surface methodology and artificial neural network. Ultrasonics sonochemistry 51:264-280

20. Ghaedi M, Mazaheri H, Khodadoust S, Hajati S, Purkait M (2015) Application of central composite design for simultaneous removal of methylene blue and $\mathrm{Pb}^{2+}$ ions by walnut wood activated carbon. Spectrochimica Acta Part A: Molecular and Biomolecular Spectroscopy 135:479-490

21. Istratie R, Stoia M, Păcurariu C, Locovei C (2019) Single and simultaneous adsorption of methyl orange and phenol onto magnetic iron oxide/carbon nanocomposites. Arabian Journal of Chemistry 12:37043722

22. Shekarriz M, Ramezani Z, Elhami F (2017) Preparation and characterization of ZSM5-supported nanozero-valent iron and its potential application in nitrate remediation from aqueous solution. International Journal of Environmental Science and Technology 14:1081-1090

23. Ahmadi M, Foladivanda M, Jaafarzadeh N, Ramezani Z, Ramavandi B, Jorfi S, Kakavandi B (2017) Synthesis of chitosan zero-valent iron nanoparticles-supported for cadmium removal: characterization, optimization and modeling approach. Journal of Water Supply: Research and Technology-Aqua $66: 116-130$

24. Baran T, Y1lmaz Baran N, Menteş A (2018) Sustainable chitosan/starch composite material for stabilization of palladium nanoparticles: synthesis, characterization and investigation of catalytic behaviour of Pd@ chitosan/starch nanocomposite in Suzuki-Miyaura reaction. Applied Organometallic Chemistry 32:e4075 
25. Fei Liu X, Lin Guan Y, Zhi Yang D, Li Z, De Yao K (2001) Antibacterial action of chitosan and carboxymethylated chitosan. Journal of applied polymer science 79:1324-1335

26. Yazdi F, Anbia M, Salehi S (2019) Characterization of functionalized chitosan-clinoptilolite nanocomposites for nitrate removal from aqueous media. International journal of biological macromolecules 130:545-555

27. Sahin M, Kocak N, Arslan G, Ucan HIJJoI, Polymers O, Materials (2011) Synthesis of crosslinked chitosan with epichlorohydrin possessing two novel polymeric ligands and its use in metal removal. Journal of Inorganic and Organometallic Polymers and Materials 21:69-80

28. Chatterjee S, Woo SH (2009) The removal of nitrate from aqueous solutions by chitosan hydrogel beads. Journal of hazardous materials 164:1012-1018

29. Ngah WW, Musa A (1998) Adsorption of humic acid onto chitin and chitosan. Journal of Applied Polymer Science 69:2305-2310

30. Lin J, Zhan Y (2012) Adsorption of humic acid from aqueous solution onto unmodified and surfactantmodified chitosan/zeolite composites. Chemical engineering journal 200:202-213

31. Zhao L, Luo F, Wasikiewicz JM, Mitomo H, Nagasawa N, Yagi T, Tamada M, Yoshii F (2008) Adsorption of humic acid from aqueous solution onto irradiation-crosslinked carboxymethylchitosan. Bioresource technology 99:1911-1917

32. Ngah WW, Hanafiah M, Yong S (2008) Adsorption of humic acid from aqueous solutions on crosslinked chitosan-epichlorohydrin beads: kinetics and isotherm studies. Colloids and Surfaces B: Biointerfaces 65:18-24

33. Chatterjee S, Lee DS, Lee MW, Woo SH (2009) Nitrate removal from aqueous solutions by crosslinked chitosan beads conditioned with sodium bisulfate. Journal of Hazardous Materials 166:508-513

34. Rajeswari A, Amalraj A, Pius A (2016) Adsorption studies for the removal of nitrate using chitosan/PEG and chitosan/PVA polymer composites. Journal of Water Process Engineering 9:123-134 
35. Teimouri A, Nasab SG, Vahdatpoor N, Habibollahi S, Salavati H, Chermahini AN (2016) Chitosan/Zeolite $\mathrm{Y} / \mathrm{Nano} \mathrm{ZrO}_{2}$ nanocomposite as an adsorbent for the removal of nitrate from the aqueous solution. International journal of biological macromolecules 93:254-266

36. Lu H, Qiao X, Wang W, Tan F, Sun F, Xiao Z, Chen J (2015) Effective removal of cadmium ions from aqueous solution using chitosan-stabilized nano zero-valent iron. Desalination and Water Treatment $56: 256-265$

37. Holak W (1969) Gas-sampling technique for arsenic determination by atomic absorption spectrophotometry. Analytical chemistry 41:1712-1713

38. Anbia M, Rahimi F (2017) Adsorption of platinum (IV) from an aqueous solution with magnetic cellulose functionalized with thiol and amine as a nano-active adsorbent. Journal of Applied Polymer Science 134:45361

39. Alslaibi TM, Abustan I, Ahmad MA, Foul AA (2013) Application of response surface methodology (RSM) for optimization of $\mathrm{Cu}^{2+}, \mathrm{Cd}^{2+}, \mathrm{Ni}^{2+}, \mathrm{Pb}^{2+}, \mathrm{Fe}^{2+}$, and $\mathrm{Zn}^{2+}$ removal from aqueous solution using microwaved olive stone activated carbon. Journal of Chemical Technology \& Biotechnology 88:21412151

40. Dil EA, Ghaedi M, Asfaram A (2017) The performance of nanorods material as adsorbent for removal of azo dyes and heavy metal ions: application of ultrasound wave, optimization and modeling. Ultrasonics Sonochemistry 34:792-802

41. Adabavazeh H, Saljooqi A, Shamspur T, Mostafavi A (2020) Synthesis of KIT-5 decorated by $\mathrm{Bi}_{2} \mathrm{~S}_{3^{-}}$ $\mathrm{Fe}_{3} \mathrm{O}_{4}$ photocatalyst for degradation of parathion pesticide in aqueous media: Offering a degradation model and optimization using response surface methodology (RSM). Applied Organometallic Chemistry 34:e5345

42. Hiew BYZ, Lee LY, Lai KC, Gan S, Thangalazhy-Gopakumar S, Pan G-T, Yang TC-KJEr (2019) Adsorptive decontamination of diclofenac by three-dimensional graphene-based adsorbent: Response surface methodology, adsorption equilibrium, kinetic and thermodynamic studies. Environmental Research 168:241-253 
43. Shaban M, Abukhadra MR, Mohamed AS, Shahien MG, Ibrahim SSJJoI, Polymers O, Materials (2018) Synthesis of mesoporous graphite functionalized by nitrogen for efficient removal of safranin dye utilizing rice husk ash; equilibrium studies and response surface optimization. Journal of Inorganic and Organometallic Polymers and Materials 28:279-294

44. Salehi S, Alijani S, Anbia M (2020) Enhanced adsorption properties of zirconium modified chitosanzeolite nanocomposites for vanadium ion removal. International Journal of Biological Macromolecules $164: 105-120$

45. Geng B, Jin Z, Li T, Qi X (2009) Preparation of chitosan-stabilized $\mathrm{Fe}^{0}$ nanoparticles for removal of hexavalent chromium in water. Science of the Total Environment 407:4994-5000

46. Yoadsomsuay T, Grisdanurak N, Liao C-H (2016) Influence of chitosan on modified nanoscale zerovalent iron for arsenate removal. Desalination and Water Treatment 57:17861-17869

47. Dong C, Chen W, Liu C (2014) Preparation of novel magnetic chitosan nanoparticle and its application for removal of humic acid from aqueous solution. Applied Surface Science 292:1067-1076

48. Liang Y-Y, Zhang L-M (2007) Bioconjugation of papain on superparamagnetic nanoparticles decorated with carboxymethylated chitosan. Biomacromolecules 8:1480-1486

49. Lu H, Qiao X, Wang W, Tan F, Xiao Z, Chen J (2014) Chitosan stabilised nanozero-valent iron for the catalytic reduction of p-nitrophenol. Micro \& Nano Letters 9:446-450

50. Salehi S, Anbia M (2019) Performance comparison of chitosan-clinoptilolite nanocomposites as adsorbents for vanadium in aqueous media. Cellulose 26:5321-5345

51. Badawy ME, Ahmed S, Rabea EI (2006) Bactericidal and fungicidal activities of different molecular weight chitosan samples. Journal of Pest Control and Environmental Sciences 14:19-34

52. Mohammadi A, Hashemi M, Hosseini SM (2016) Effect of chitosan molecular weight as micro and nanoparticles on antibacterial activity against some soft rot pathogenic bacteria. LWT-Food Science and Technology 71:347-355

53. Hosseinnejad M, Jafari SM (2016) Evaluation of different factors affecting antimicrobial properties of chitosan. International journal of biological macromolecules 85:467-475 
54. Muzzarelli R (1973) Natural chelating polymers International series of monographs in analytical chemistry. Pergamon Press, Oxford, UK

55. Jovanĉić P, Jocić D, Molina R, Julia MR, Erra P (2001) Shrinkage properties of peroxide-enzymebiopolymer treated wool. Textile Research Journal 71:948-953

56. Palza H (2015) Antimicrobial polymers with metal nanoparticles. International journal of molecular sciences 16:2099-2116

57. Yan J, Qian L, Gao W, Chen Y, Ouyang D, Chen M (2017) Enhanced Fenton-like degradation of trichloroethylene by hydrogen peroxide activated with nanoscale zero valent iron loaded on biochar. Scientific reports 7:1-9

58. Lemire JA, Harrison JJ, Turner RJ (2013) Antimicrobial activity of metals: mechanisms, molecular targets and applications. Nature Reviews Microbiology 11:371-384

59. Chen Q, Li J, Wu Y, Shen F, Yao M (2013) Biological responses of Gram-positive and Gram-negative bacteria to nZVI $\left(\mathrm{Fe}^{0}\right), \mathrm{Fe}^{2+}$ and $\mathrm{Fe}^{3+}$. RSC advances 3:13835-13842

60. Slavin YN, Asnis J, Häfeli UO, Bach H (2017) Metal nanoparticles: understanding the mechanisms behind antibacterial activity. Journal of nanobiotechnology 15 (1):65

61. Jiang Z, Lv L, Zhang W, Du Q, Pan B, Yang L, Zhang Q (2011) Nitrate reduction using nanosized zerovalent iron supported by polystyrene resins: role of surface functional groups. Water research 45:21912198

62. Vindedahl AM, Strehlau JH, Arnold WA, Penn RL (2016) Organic matter and iron oxide nanoparticles: aggregation, interactions, and reactivity. Environmental Science: Nano 3:494-505

63. Bhatnagar A, Sillanpää M (2011) A review of emerging adsorbents for nitrate removal from water. Chemical Engineering Journal 168:493-504

64. Wang L, Zhou H, Liu J, Chen J, Wei S, Jiang Z (2018) Effect of Humic Acid on the Nitrate Removal by Strong Base Anion Exchanger Supported Nanoscale Zero-valent Iron Composite. Water, Air, \& Soil Pollution 229:357 
65. Xie L, Shang C (2005) Role of humic acid and quinone model compounds in bromate reduction by zerovalent iron. Environmental science \& technology 39:1092-1100

66. Ekebafe LO, Ogbeifun DE, Okieimen FEJJoP, Environment t (2018) Equilibrium, kinetic and thermodynamic studies of lead (II) sorption on hydrolyzed starch graft copolymers. Journal of Polymers and the Environment 26:807-818

67. Jawad AH, Mubarak NSA, Abdulhameed ASJJoP, Environment t (2020) Hybrid crosslinked chitosanepichlorohydrin/TiO 2 nanocomposite for reactive red 120 dye adsorption: kinetic, isotherm, thermodynamic, and mechanism study. Journal of Polymers and the Environment 28:624-637 


\section{Table caption}

Table 1 Antibacterial activity of net chitosan.

Table 2 Experimental Levels and results of CCD.

Table 3 Analysis of variance for nitrate removal.

Table 4 Analysis of variance for HA removal.

Table 5 Kinetic parameters for the removal of nitrate and HA from the binary system.

Table 6 Isotherm parameters for the removal of nitrate and HA from the binary system.

Figure caption:

Fig. 1 FTIR spectra of cellulose (a), chitosan (b) and nZVI/chitosan (c)

Fig. $2 \mathrm{~N}_{2}$ adsorption and desorption isotherm of cellulose, chitosan and nZVI/chitosan

Fig. 3 XRD patterns for cellulose (a), chitosan (b) and nZVI/chitosan (c)

Fig. 4 EDX with mapping analysis of cellulose (a), chitosan (b) and nZVI/chitosan (c)

Fig. 5 TEM of nZVI/chitosan

Fig. 6 Hysteresis loop of nZVI/chitosan.

Fig. 7 Antibacterial activities of nZVI/chitosan.

Fig. 8 Diameter values of inhibition for nZVI/chitosan against pathogenic bacteria

Fig. 9 The possible mechanism antibacterial of nZVI/chitosan 
Fig. 10 HA uptakes onto cellulose, chitosan and nZVI/chitosan $(\mathrm{pH}=5.5, \mathrm{~T}=$ room temperature, $\mathrm{t}=27 \mathrm{~min}$, composite dose $=0.01 \mathrm{mg} / \mathrm{L}$ )

Fig. 11 Response surface plots for nitrate and HA adsorption onto nZVI/chitosan (composite dose and $\mathrm{pH}(\mathrm{a}$ and $\mathrm{b})$, contact time and composite dose (c and d) and nitrate concentration and HA concentration (e and $\mathrm{f})$ )

Fig. 12 FT-IR spectrums of nZVI/chitosan after reaction with HA (a) and the HA/nitrate (b) binary system at acidic conditions 
Table 1 Antibacterial activity of net chitosan

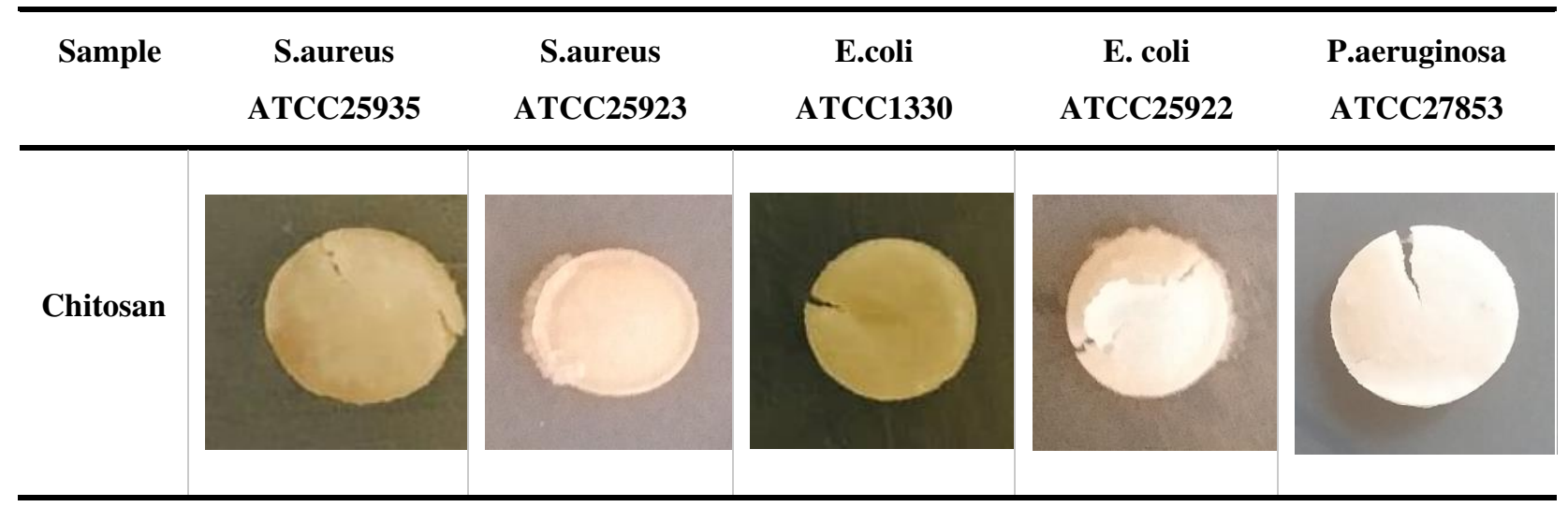


Table 2 Experimental Levels and results of CCD

\begin{tabular}{|c|c|c|c|c|c|c|c|}
\hline \multirow{2}{*}{ Factor } & \multicolumn{4}{|c|}{ Level } & \multicolumn{3}{|c|}{ Star Point } \\
\hline & Low (-1) & Central (0) & & High (+1) & & $-\alpha$ & $+\alpha$ \\
\hline $\mathrm{A}(\mathrm{pH})$ & 0.5 & 5.5 & & 10.5 & & 0.5 & 10.5 \\
\hline B (Contact time) & 7.5 & 42.5 & & 77.5 & & 7.5 & 77.5 \\
\hline $\mathrm{C}$ (Nitrate Con) & 50 & 150 & & 250 & & 50 & 250 \\
\hline D (HA Con) & 10 & 50 & & 90 & & 10 & 90 \\
\hline $\mathrm{E}($ dose $)$ & 0.025 & 0.075 & & 0.125 & & 0.025 & 0.125 \\
\hline Run & A & B & $\mathrm{C}$ & D & E & $\mathrm{R} \% \mathrm{NO}^{3-}$ & $\mathrm{R} \% \mathrm{HA}$ \\
\hline 1 & 8 & 60 & 100 & 70 & 0.05 & 74 & 90.8 \\
\hline 2 & 3 & 25 & 100 & 30 & 0.05 & 84.4 & 94.8 \\
\hline 3 & 8 & 25 & 200 & 70 & 0.05 & 76.1 & 92.5 \\
\hline 4 & 3 & 60 & 200 & 30 & 0.1 & 84.9 & 99 \\
\hline 5 & 8 & 25 & 100 & 70 & 0.1 & 78.2 & 94.4 \\
\hline 6 & 3 & 60 & 100 & 70 & 0.1 & 87.7 & 99 \\
\hline 7 & 8 & 60 & 100 & 30 & 0.1 & 79.1 & 92.1 \\
\hline 8 & 8 & 60 & 200 & 30 & 0.05 & 83.8 & 95.5 \\
\hline 9 & 8 & 25 & 200 & 30 & 0.1 & 82.7 & 95.8 \\
\hline 10 & 3 & 25 & 200 & 70 & 0.05 & 84 & 95.5 \\
\hline 11 & 5.5 & 42.5 & 150 & 50 & 0.1 & 85 & 96.5 \\
\hline 12 & 5.5 & 42.5 & 150 & 50 & 0.1 & 85 & 97 \\
\hline 13 & 5.5 & 42.5 & 150 & 50 & 0.075 & 85.2 & 97 \\
\hline 14 & 3 & 60 & 200 & 70 & 0.05 & 86.5 & 94.7 \\
\hline 15 & 5.5 & 42.5 & 150 & 50 & 0.075 & 85.1 & 96 \\
\hline 16 & 5.5 & 42.5 & 50 & 50 & 0.075 & 84.3 & 95 \\
\hline 17 & 5.5 & 77.5 & 150 & 50 & 0.075 & 78.3 & 97.8 \\
\hline 18 & 0.5 & 42.5 & 150 & 50 & 0.075 & 90.7 & 77 \\
\hline 19 & 5.5 & 42.5 & 150 & 50 & 0.125 & 86 & 99 \\
\hline 20 & 5.5 & 42.5 & 150 & 90 & 0.075 & 79.4 & 95 \\
\hline 21 & 5.5 & 7.5 & 150 & 50 & 0.075 & 80 & 95.1 \\
\hline 22 & 5.5 & 42.5 & 150 & 10 & 0.075 & 89.4 & 99 \\
\hline 23 & 5.5 & 42.5 & 250 & 50 & 0.075 & 79.4 & 98.5 \\
\hline 24 & 5.5 & 42.5 & 150 & 50 & 0.075 & 85 & 96.1 \\
\hline 25 & 5.5 & 42.5 & 150 & 50 & 0.075 & 85 & 95 \\
\hline 26 & 10.5 & 42.5 & 150 & 50 & 0.075 & 77 & 92 \\
\hline 27 & 5.5 & 42.5 & 150 & 50 & 0.025 & 81.5 & 91.9 \\
\hline
\end{tabular}


Table 3 Analysis of variance for nitrate removal.

\begin{tabular}{|c|c|c|c|c|c|c|}
\hline Source & $\begin{array}{l}\text { Sum of } \\
\text { Squares }\end{array}$ & df & $\begin{array}{l}\text { Mean } \\
\text { Square }\end{array}$ & F-value & p-value & \\
\hline Block & 0.3227 & 1 & 0.3227 & & & \\
\hline Model & 439.19 & 20 & 21.96 & 3444.28 & $<0.0001$ & Significant \\
\hline A-pH & 93.84 & 1 & 93.84 & 14719.22 & $<0.0001$ & \\
\hline B-Time & 1.44 & 1 & 1.44 & 226.64 & $<0.0001$ & \\
\hline $\mathrm{C}-\mathrm{NO}_{3}{ }^{-} \mathrm{Con}$. & 12.00 & 1 & 12.00 & 1882.94 & $<0.0001$ & \\
\hline D- HA Con & 50.00 & 1 & 50.00 & 7842.31 & $<0.0001$ & \\
\hline E-dose & 10.13 & 1 & 10.13 & 1588.07 & $<0.0001$ & \\
\hline $\mathrm{AB}$ & 4.88 & 1 & 4.88 & 765.88 & $<0.0001$ & \\
\hline $\mathrm{AC}$ & 3.56 & 1 & 3.56 & 557.96 & $<0.0001$ & \\
\hline $\mathrm{AD}$ & 5.51 & 1 & 5.51 & 864.57 & $<0.0001$ & \\
\hline $\mathrm{AE}$ & 13.22 & 1 & 13.22 & 2074.03 & $<0.0001$ & \\
\hline $\mathrm{BC}$ & 4.68 & 1 & 4.68 & 733.29 & $<0.0001$ & \\
\hline $\mathrm{BD}$ & 1.66 & 1 & 1.66 & 260.13 & $<0.0001$ & \\
\hline $\mathrm{BE}$ & 14.25 & 1 & 14.25 & 2234.51 & $<0.0001$ & \\
\hline $\mathrm{CD}$ & 4.10 & 1 & 4.10 & 642.64 & $<0.0001$ & \\
\hline $\mathrm{CE}$ & 5.51 & 1 & 5.51 & 864.57 & $<0.0001$ & \\
\hline $\mathrm{DE}$ & 0.6132 & 1 & 0.6132 & 96.19 & 0.0002 & \\
\hline $\mathrm{A}^{2}$ & 2.18 & 1 & 2.18 & 341.42 & $<0.0001$ & \\
\hline $\mathrm{B}^{2}$ & 59.97 & 1 & 59.97 & 9405.86 & $<0.0001$ & \\
\hline $\mathrm{C}^{2}$ & 17.16 & 1 & 17.16 & 2692.00 & $<0.0001$ & \\
\hline $\mathrm{D}^{2}$ & 0.5503 & 1 & 0.5503 & 86.32 & $<0.0002$ & \\
\hline$E^{2}$ & 2.59 & 1 & 2.59 & 405.94 & $<0.0001$ & \\
\hline Residual & 0.0319 & 5 & 0.0064 & & & \\
\hline Lack of Fit & 0.0044 & 1 & 0.0044 & 0.6963 & 0.4695 & Not significant \\
\hline Pure Error & 0.0275 & 4 & 0.0069 & & & \\
\hline Core Total & 439.55 & 26 & & & & \\
\hline
\end{tabular}


Table 4 Analysis of variance for HA removal.

\begin{tabular}{|c|c|c|c|c|c|c|}
\hline Source & $\begin{array}{c}\text { Sum of } \\
\text { Squares }\end{array}$ & df & $\begin{array}{c}\text { Mean } \\
\text { Square }\end{array}$ & F-value & p-value & \\
\hline Block & 7.92 & 1 & 7.92 & & & \\
\hline Model & 463.53 & 20 & 23.18 & 87.88 & $<0.0001$ & Significant \\
\hline A-pH & 112.50 & 1 & 112.50 & 426.57 & $<0.0001$ & \\
\hline B-Time & 3.65 & 1 & 3.65 & 13.82 & 0.0137 & \\
\hline C- Nitrate Con & 6.13 & 1 & 6.13 & 23.22 & 0.0048 & \\
\hline D- HA Con & 8.00 & 1 & 8.00 & 30.33 & 0.0027 & \\
\hline E-dose & 25.20 & 1 & 25.20 & 95.57 & 0.0002 & \\
\hline $\mathrm{AB}$ & 30.43 & 1 & 30.43 & 115.40 & 0.0001 & \\
\hline $\mathrm{AC}$ & 11.56 & 1 & 11.56 & 43.82 & 0.0012 & \\
\hline $\mathrm{AD}$ & 7.59 & 1 & 7.59 & 28.79 & 0.0030 & \\
\hline $\mathrm{AE}$ & 33.03 & 1 & 33.03 & 125.22 & $<0.0001$ & \\
\hline $\mathrm{BC}$ & 22.52 & 1 & 22.52 & 85.41 & 0.0002 & \\
\hline $\mathrm{BD}$ & 36.42 & 1 & 36.42 & 138.08 & $<0.0001$ & \\
\hline $\mathrm{BE}$ & 12.27 & 1 & 12.27 & 46.54 & 0.0010 & \\
\hline $\mathrm{CD}$ & 23.41 & 1 & 23.41 & 88.75 & 0.0002 & \\
\hline $\mathrm{CE}$ & 10.42 & 1 & 10.42 & 39.49 & 0.0015 & \\
\hline $\mathrm{DE}$ & 36.42 & 1 & 36.42 & 138.08 & $<0.0001$ & \\
\hline $\mathrm{A}^{2}$ & 213.01 & 1 & 213.01 & 807.69 & $<0.0001$ & \\
\hline $\mathrm{B}^{2}$ & 1.80 & 1 & 1.80 & 6.84 & 0.0474 & \\
\hline $\mathrm{C}^{2}$ & 3.04 & 1 & 3.04 & 11.52 & 0.0194 & \\
\hline $\mathrm{D}^{2}$ & 4.31 & 1 & 4.31 & 16.35 & 0.0099 & \\
\hline $\mathrm{E}^{2}$ & 0.0001 & 1 & 0.0001 & 0.0003 & 0.9861 & \\
\hline Residual & 1.32 & 5 & 0.2637 & & & \\
\hline Lack of Fit & 0.0262 & 1 & 0.0262 & 0.0810 & 0.7901 & Not significan \\
\hline Pure Error & 1.29 & 4 & 0.3231 & & & \\
\hline Core Total & 472.77 & 26 & & & & \\
\hline
\end{tabular}


Table 5 Kinetic parameters for the removal of nitrate and HA from the binary system.

\begin{tabular}{cccc}
\hline Kinetic models & Parameters & Nitrate & HA \\
\hline & $\mathbf{K}_{\mathbf{1}}(\mathbf{L} / \mathbf{m i n})$ & 0.0045 & 0.1303 \\
Pseudo-first-order & $\mathbf{q}_{\mathbf{e}}(\mathbf{m g} / \mathbf{g})$ & 504.11 & 288.38 \\
& $\mathbf{R}^{\mathbf{2}}$ & 0.9793 & 0.9863 \\
& & & \\
Pseudo-second-order & $\mathbf{K}_{\mathbf{2}}(\mathbf{g} / \mathbf{m g} \mathbf{~ m i n})$ & 0.0015 & 0.0001 \\
& $\mathbf{q}_{\mathbf{e}}(\mathbf{m g} / \mathbf{g})$ & 113.63 & 384.61 \\
& $\mathbf{R}^{\mathbf{2}}$ & 0.9990 & 0.9998 \\
Intraparticle diffusion & $\mathbf{K}_{\mathbf{i}}\left(\mathbf{g} / \mathbf{m g} \mathbf{~ m i n} \mathbf{~}^{\mathbf{0 . 5}}\right)$ & 14.91 & 51.63 \\
& $\mathbf{R}^{\mathbf{2}}$ & 0.9951 & 0.9975 \\
\hline
\end{tabular}


Table 6 Isotherm parameters for the removal of nitrate and HA from the binary system.

\begin{tabular}{cccc}
\hline Isotherm models & Parameters & Nitrate & HA \\
\hline \multirow{2}{*}{ Langmuir } & $\mathbf{K}_{\mathbf{L}}(\mathbf{L} / \mathbf{m g})$ & 0.05 & 0.01 \\
& $\mathbf{q}_{\mathbf{m}}(\mathbf{m g} / \mathbf{g})$ & 833.33 & 312.50 \\
& $\mathbf{R}_{\mathbf{L}}$ & 0.07 & 0.43 \\
$\mathbf{R}^{\mathbf{2}}$ & 0.9976 & 0.9899 \\
& & & \\
Freundlich & $\mathbf{K}_{\mathbf{F}}(\mathbf{L} / \mathbf{g})$ & 65.45 & 43.98 \\
& $\mathbf{1 / n}$ & 0.64 & 0.60 \\
& $\mathbf{R}^{\mathbf{2}}$ & 0.9870 & 0.9920 \\
& & & \\
Temkin & $\mathbf{A}_{\mathbf{T}}$ & 1.61 & 1.47 \\
& $\mathbf{B}_{\mathbf{T}}$ & 180.85 & 66.56 \\
& $\mathbf{R}^{\mathbf{2}}$ & 0.9883 & 0.9794 \\
\hline
\end{tabular}




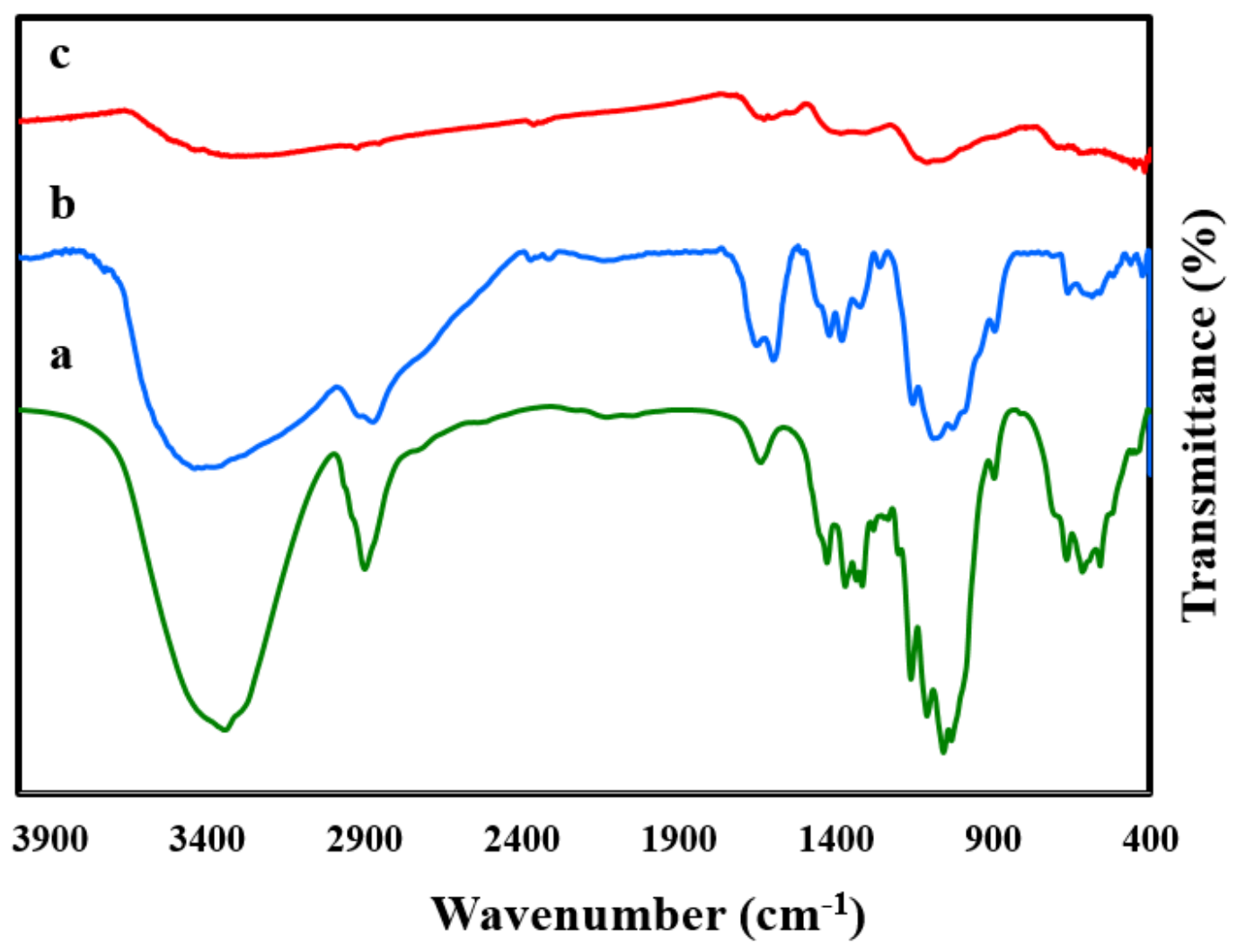

Fig. 1 FTIR spectra of cellulose (a), chitosan (b) and nZVI/chitosan (c). 


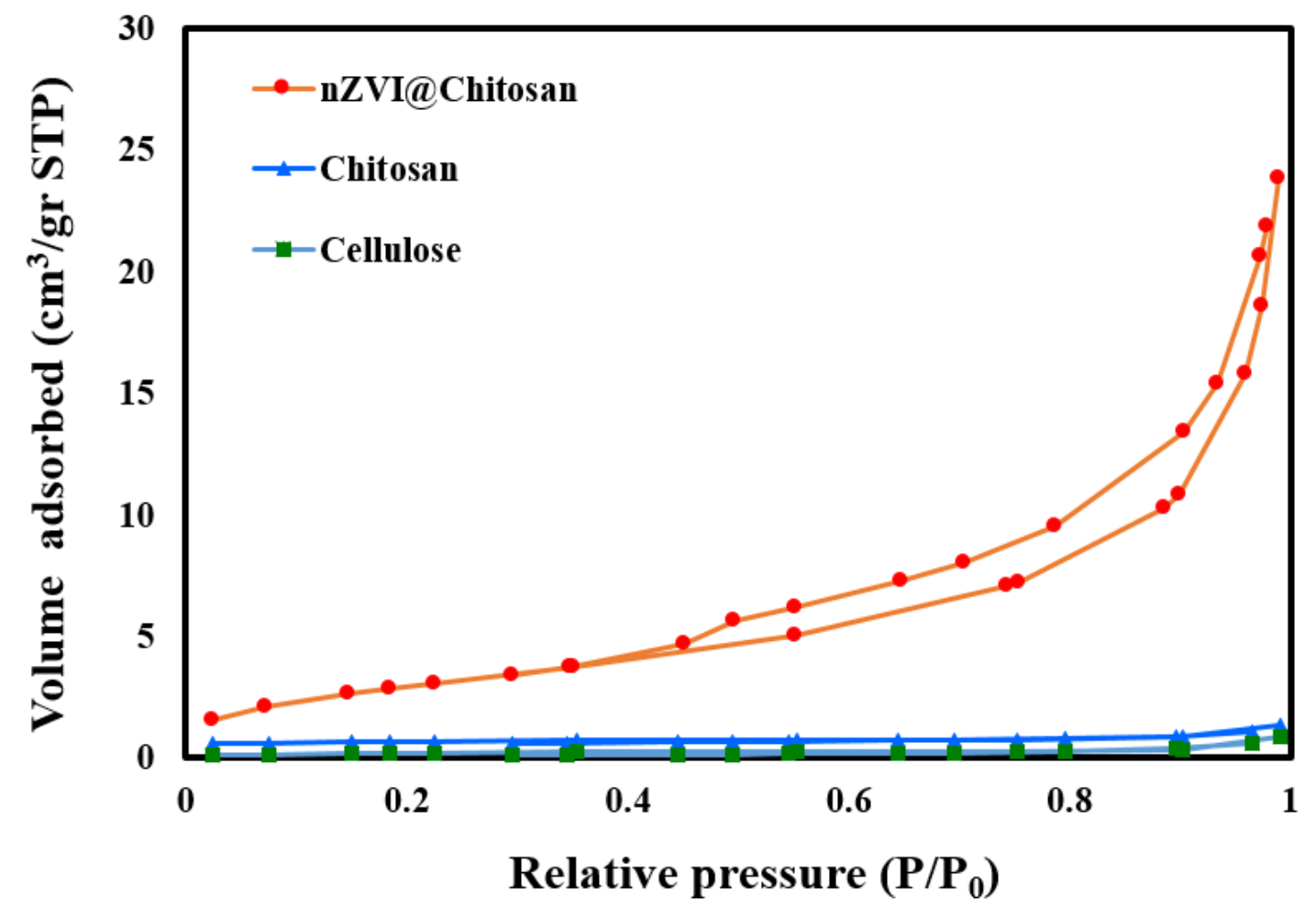

Fig. $2 \mathrm{~N}_{2}$ adsorption and desorption isotherm of cellulose, chitosan and nZVI/chitosan. 


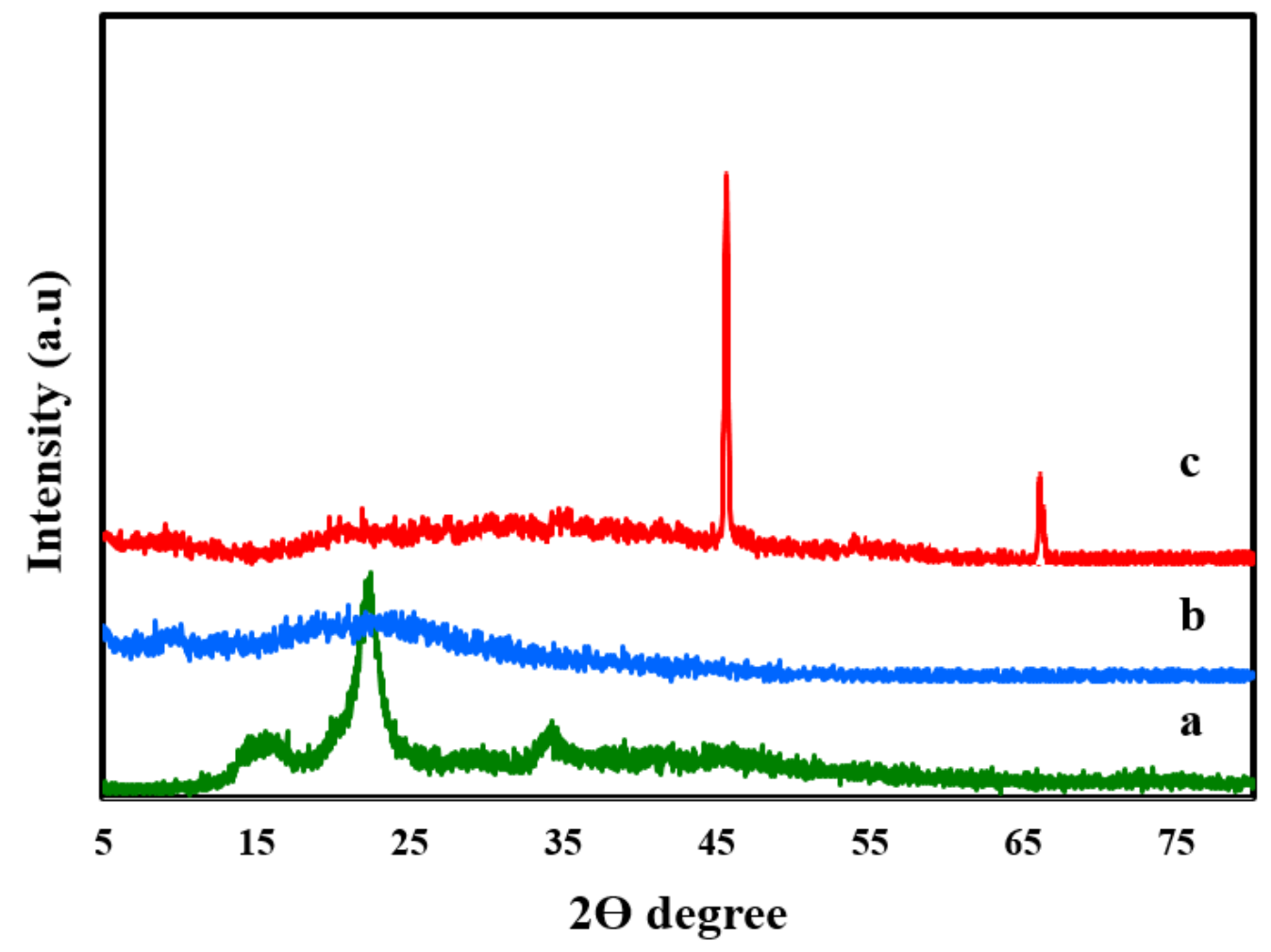

Fig. 3 XRD patterns for cellulose (a), chitosan (b) and nZVI/chitosan (c). 

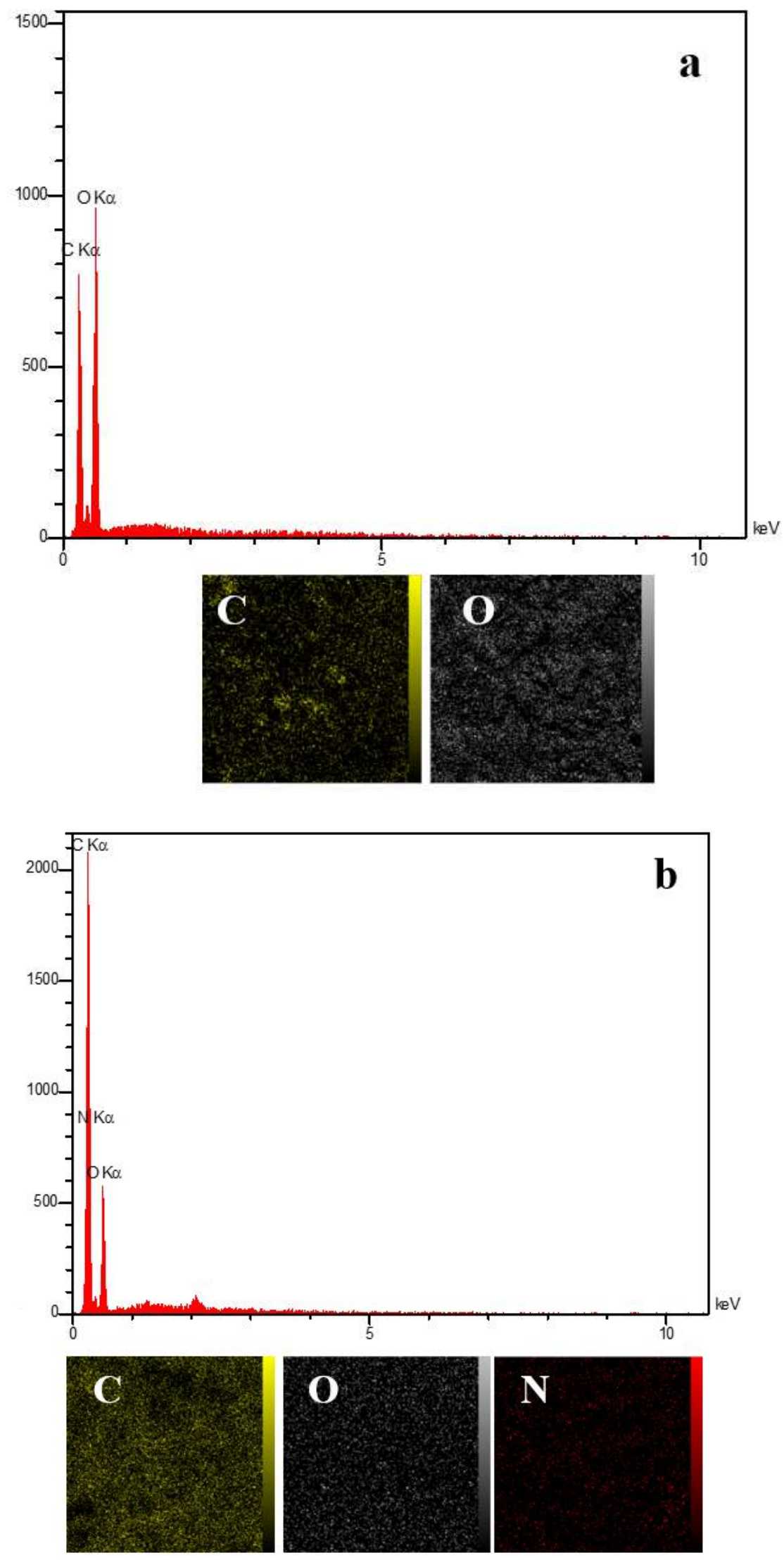


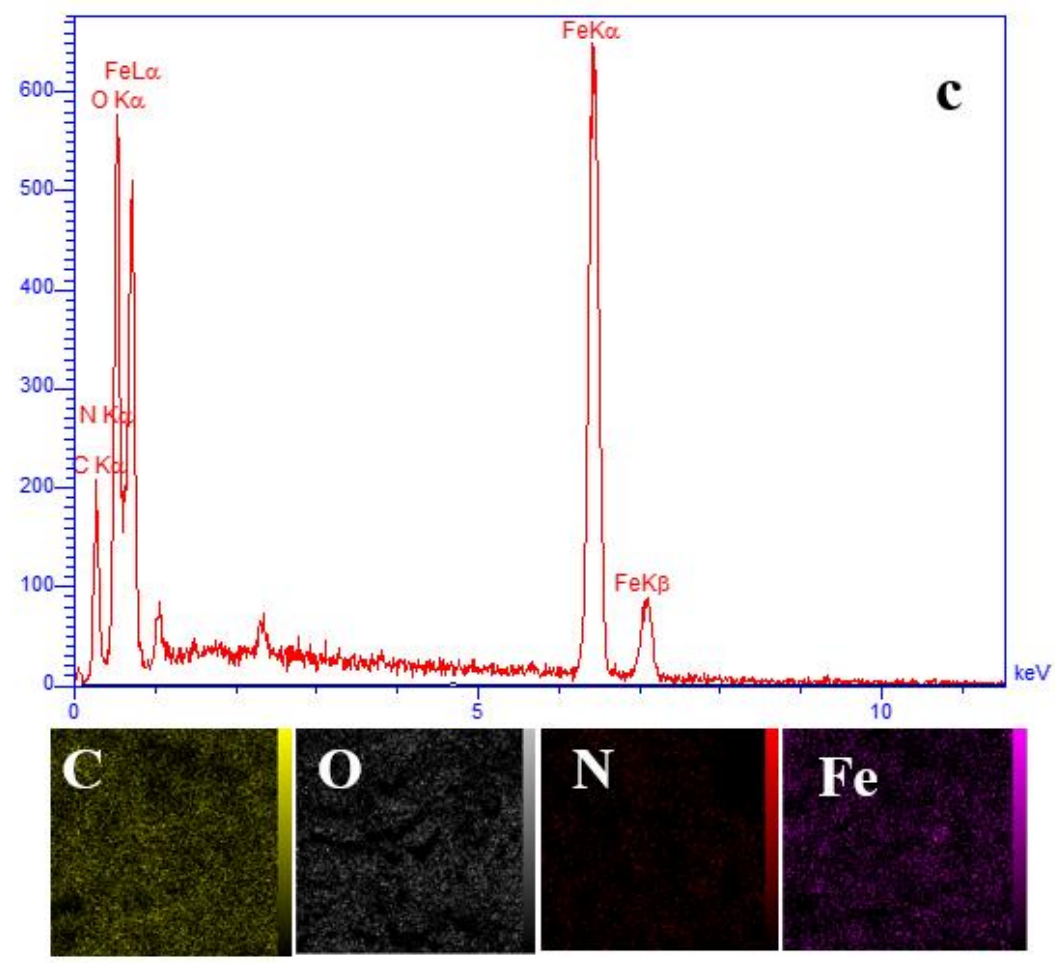

Fig. 4 EDX with mapping analysis of cellulose (a), chitosan (b) and nZVI/chitosan (c). 


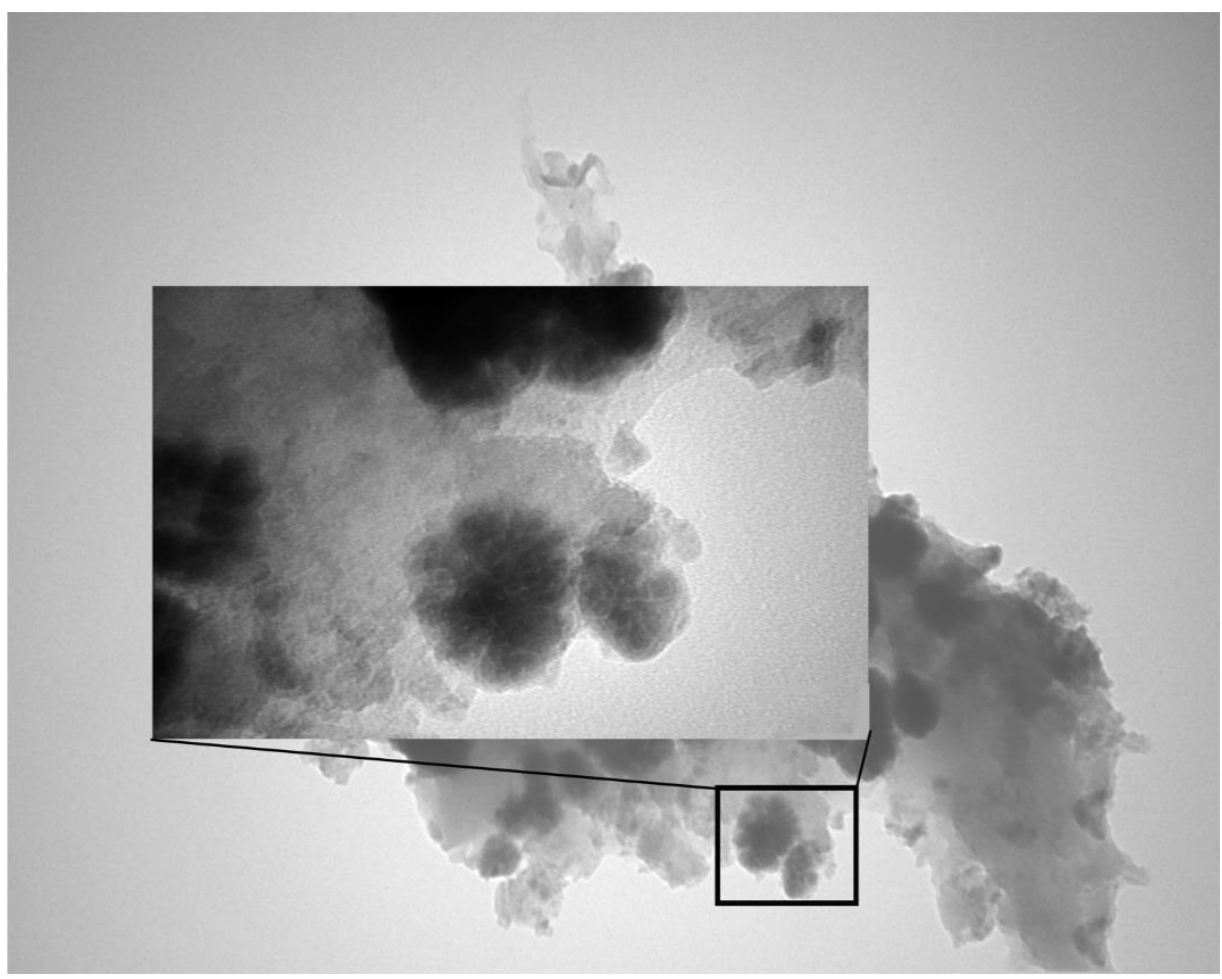

Fig. 5 TEM of nZVI/chitosan. 


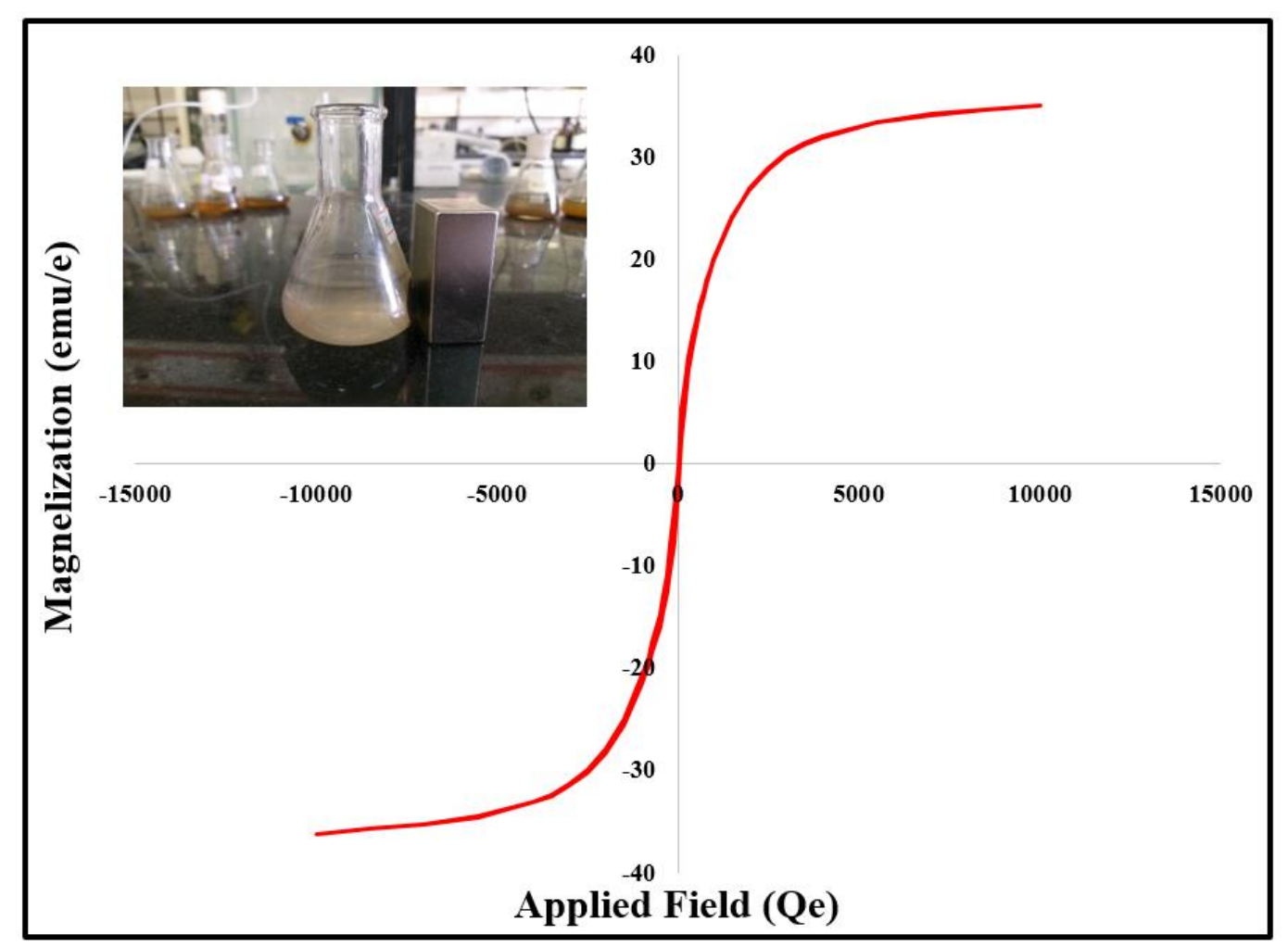

Fig. 6 Hysteresis loop of nZVI/chitosan. 


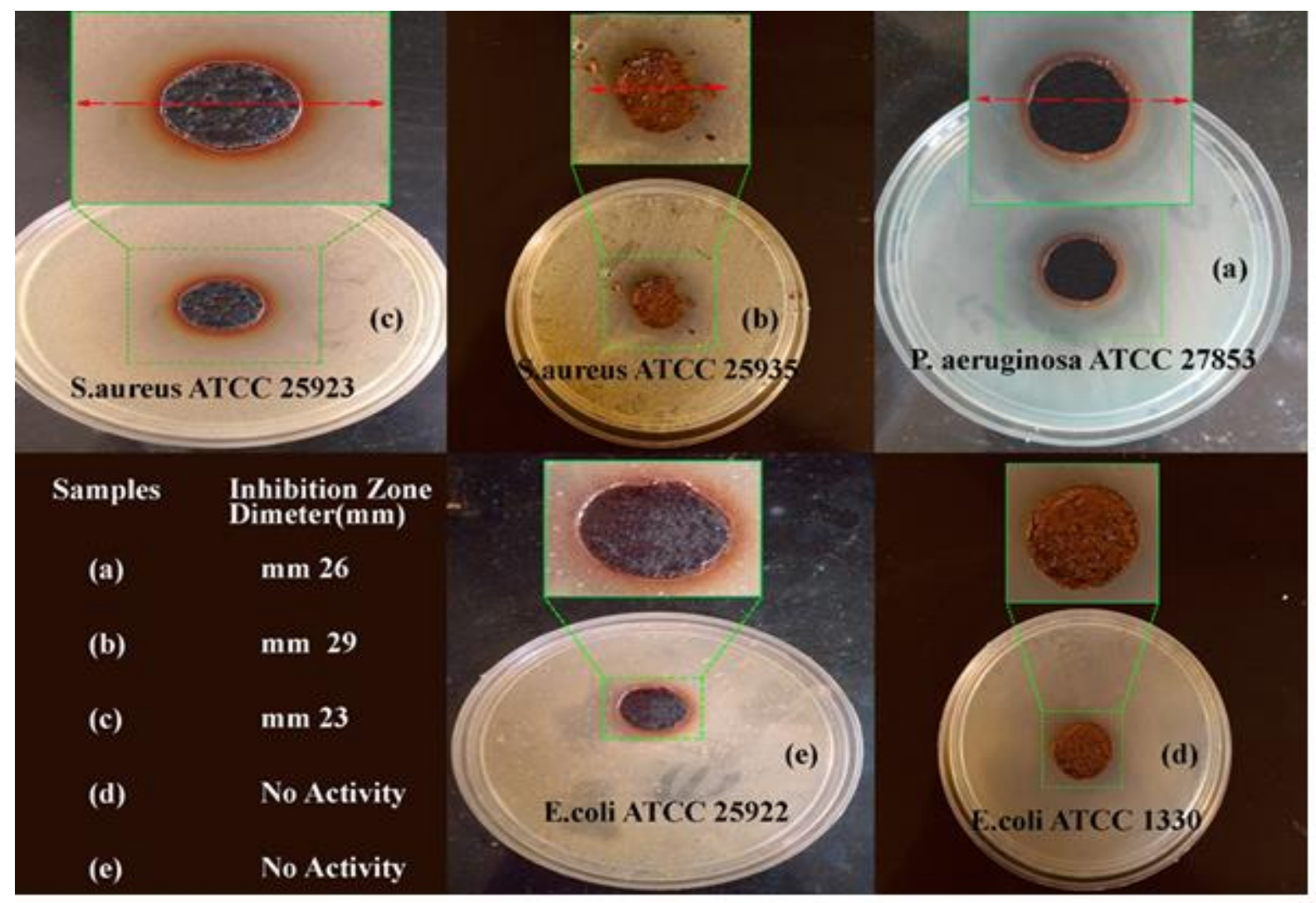

Fig. 7 Antibacterial activities of nZVI/chitosan. 


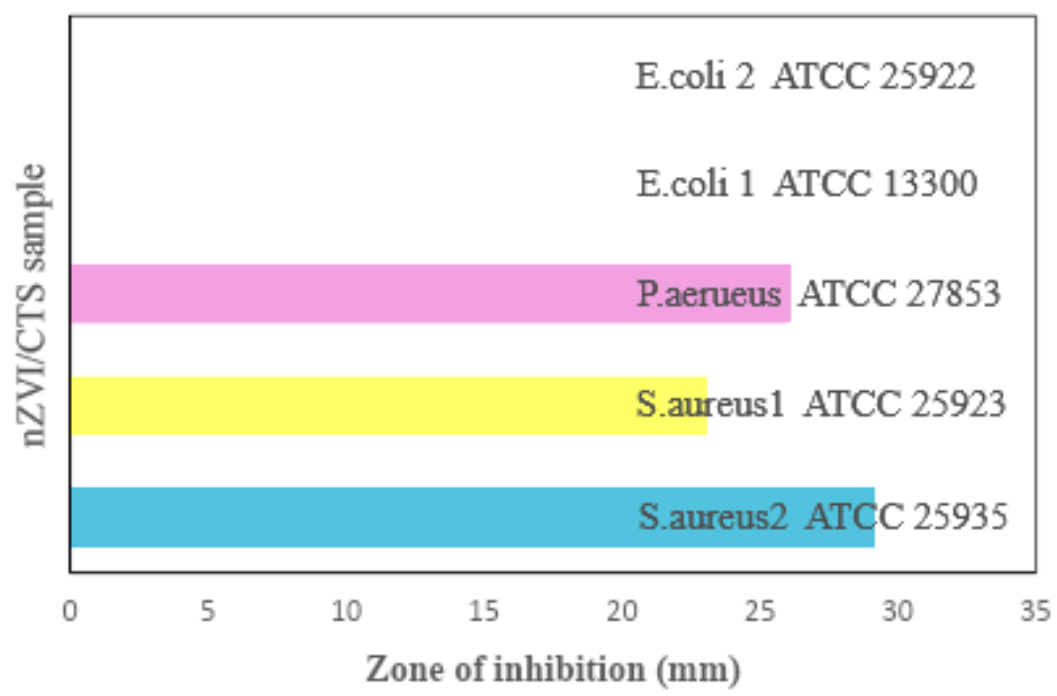

Fig. 8 Diameter values of inhibition for nZVI/chitosan against pathogenic bacteria. 


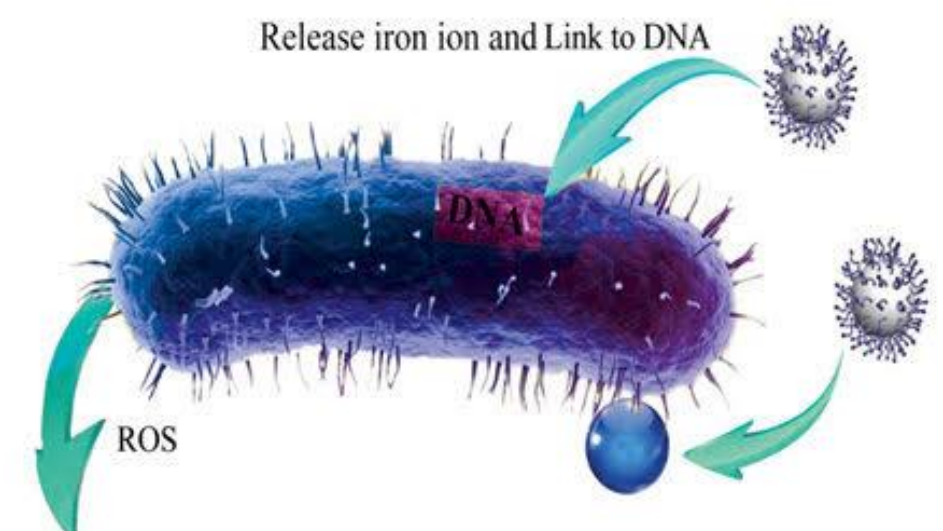

The adsorption of iron ion

$\mathrm{Fe}^{2+}+\mathrm{H}_{2} \mathrm{O}_{2} \longrightarrow \mathrm{Fe}^{3 *}+\mathrm{OH}^{*}+\mathrm{OH}^{-}$ by electronegative macromolecules nZVI/CTS

Electronegative macromolecules

Fig. 9 The possible mechanism antibacterial of nZVI/chitosan. 


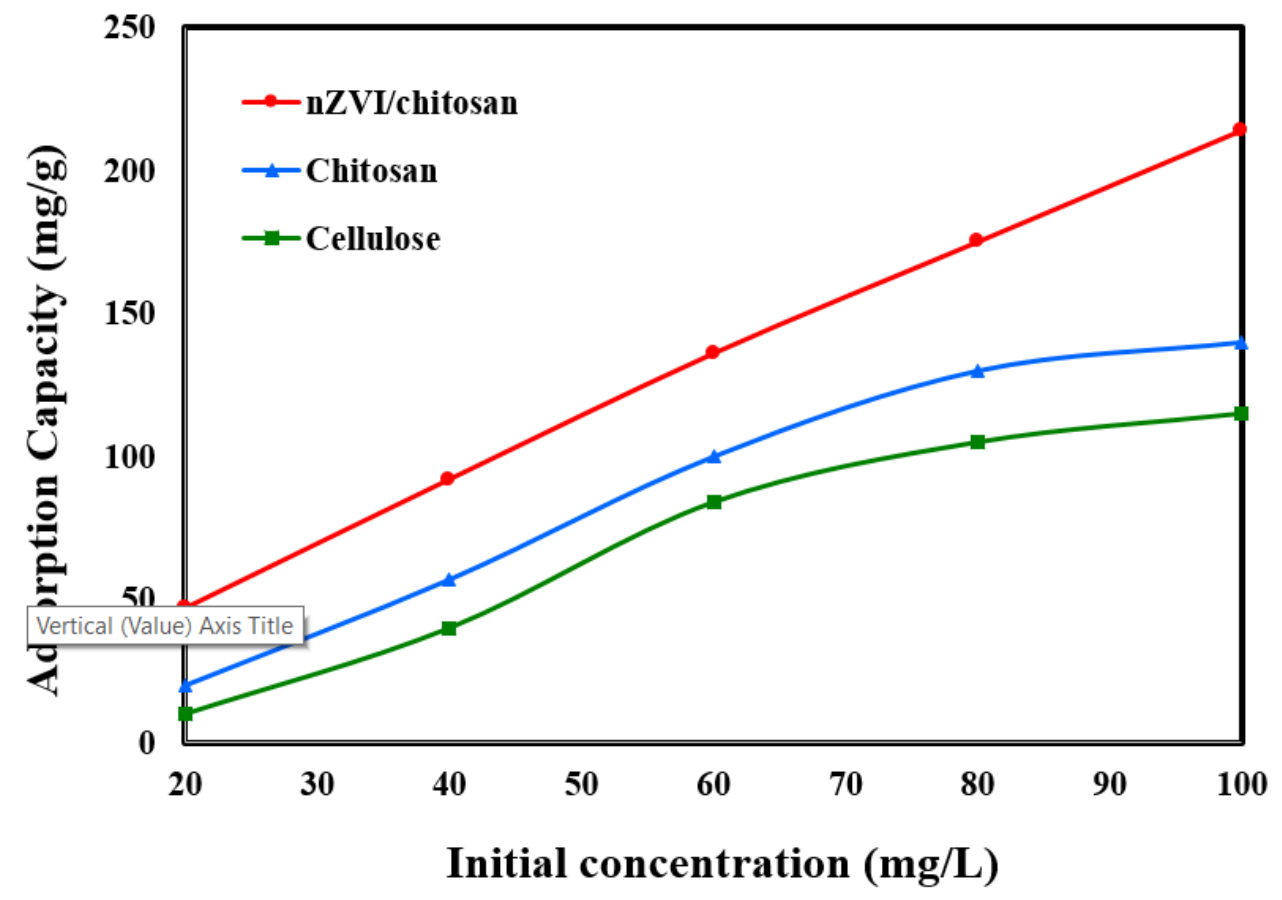

Fig. 10 HA uptakes onto cellulose, chitosan and $\mathrm{nZVI} /$ chitosan $(\mathrm{pH}=5.5, \mathrm{~T}=$ room temperature, $\mathrm{t}=27 \mathrm{~min}$, composite dose $=0.01 \mathrm{mg} / \mathrm{L})$. 

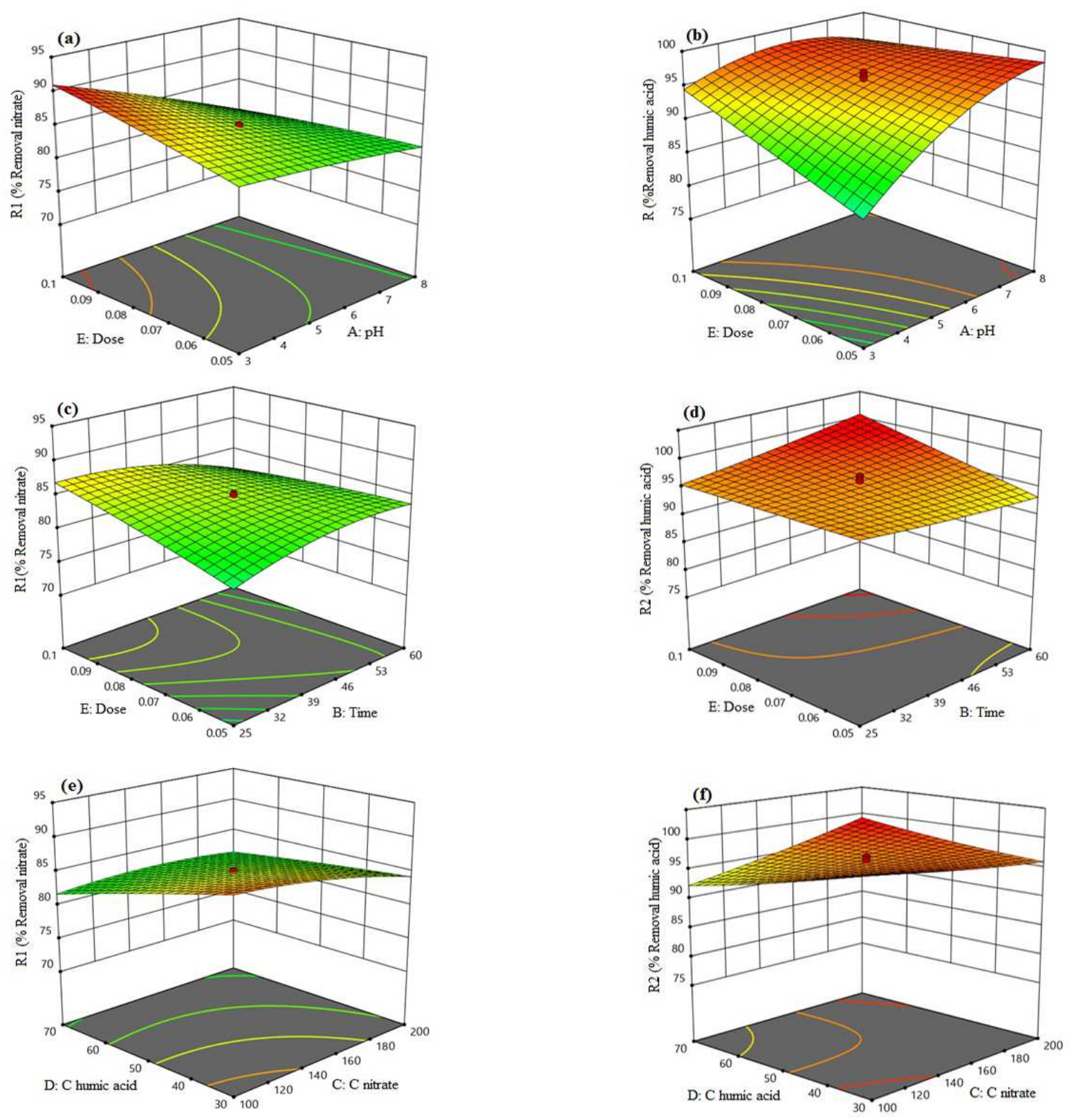

Fig. 11 Response surface plots for nitrate and HA adsorption onto nZVI/chitosan (composite dose and $\mathrm{pH}(\mathrm{a}$ and $\mathrm{b})$, contact time and composite dose (c and d) and nitrate concentration and HA concentration (e and f)). 


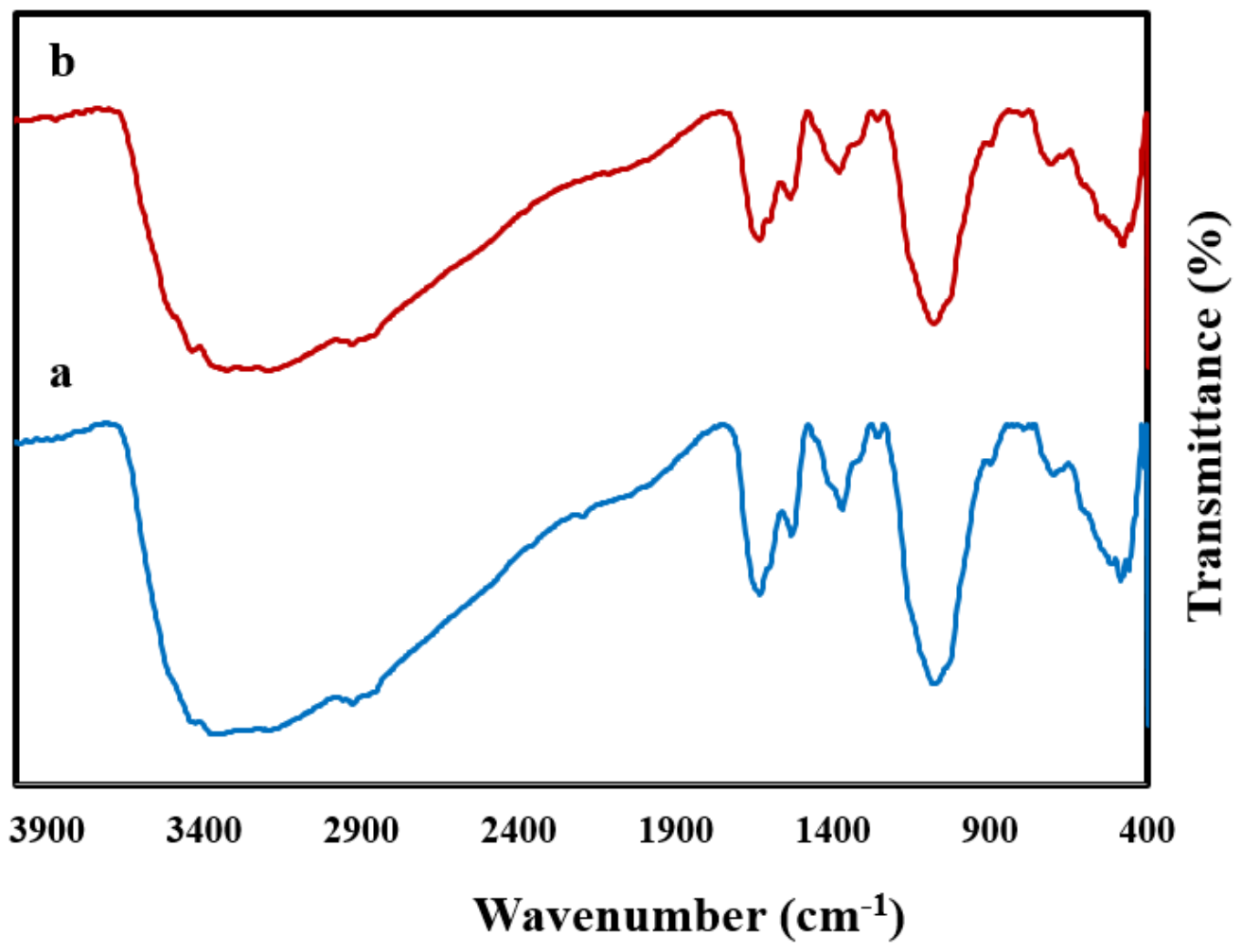

Fig. 12 FT-IR spectrums of nZVI/chitosan after reaction with HA (a) and the HA/nitrate (b) binary system at acidic conditions. 


\section{Graphical abstract}

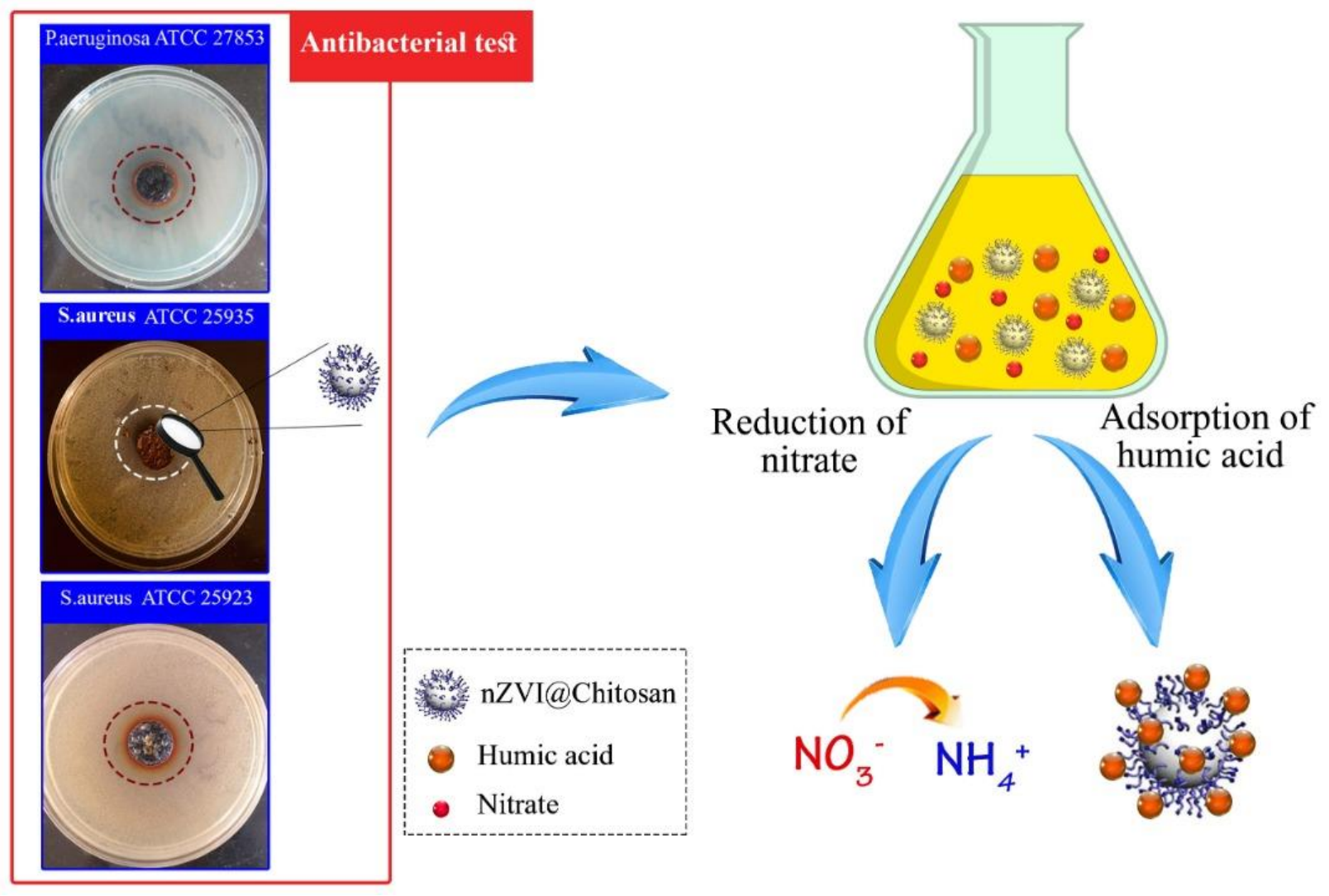


Figures

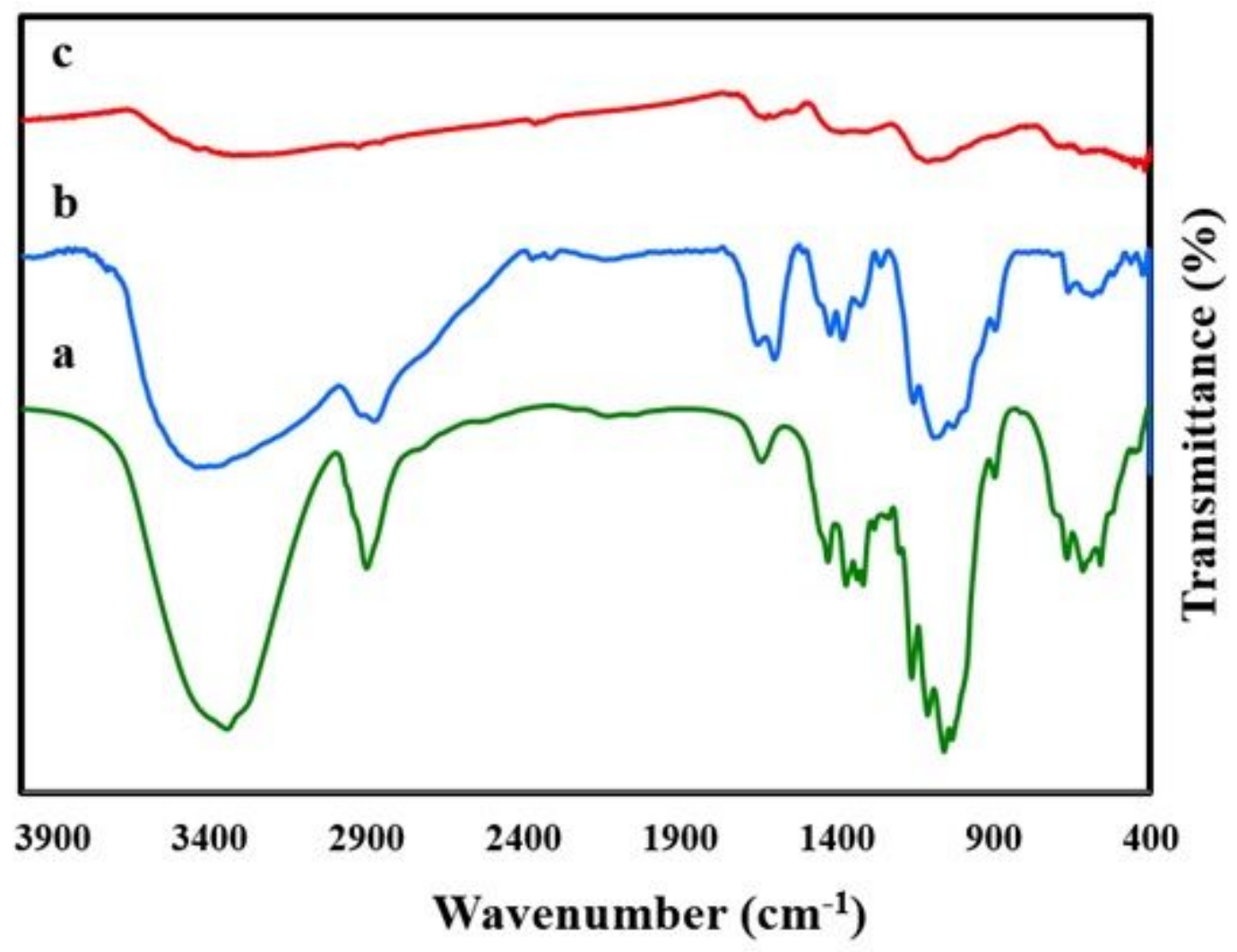

Figure 1

FTIR spectra of cellulose (a), chitosan (b) and nZVI/chitosan (c).

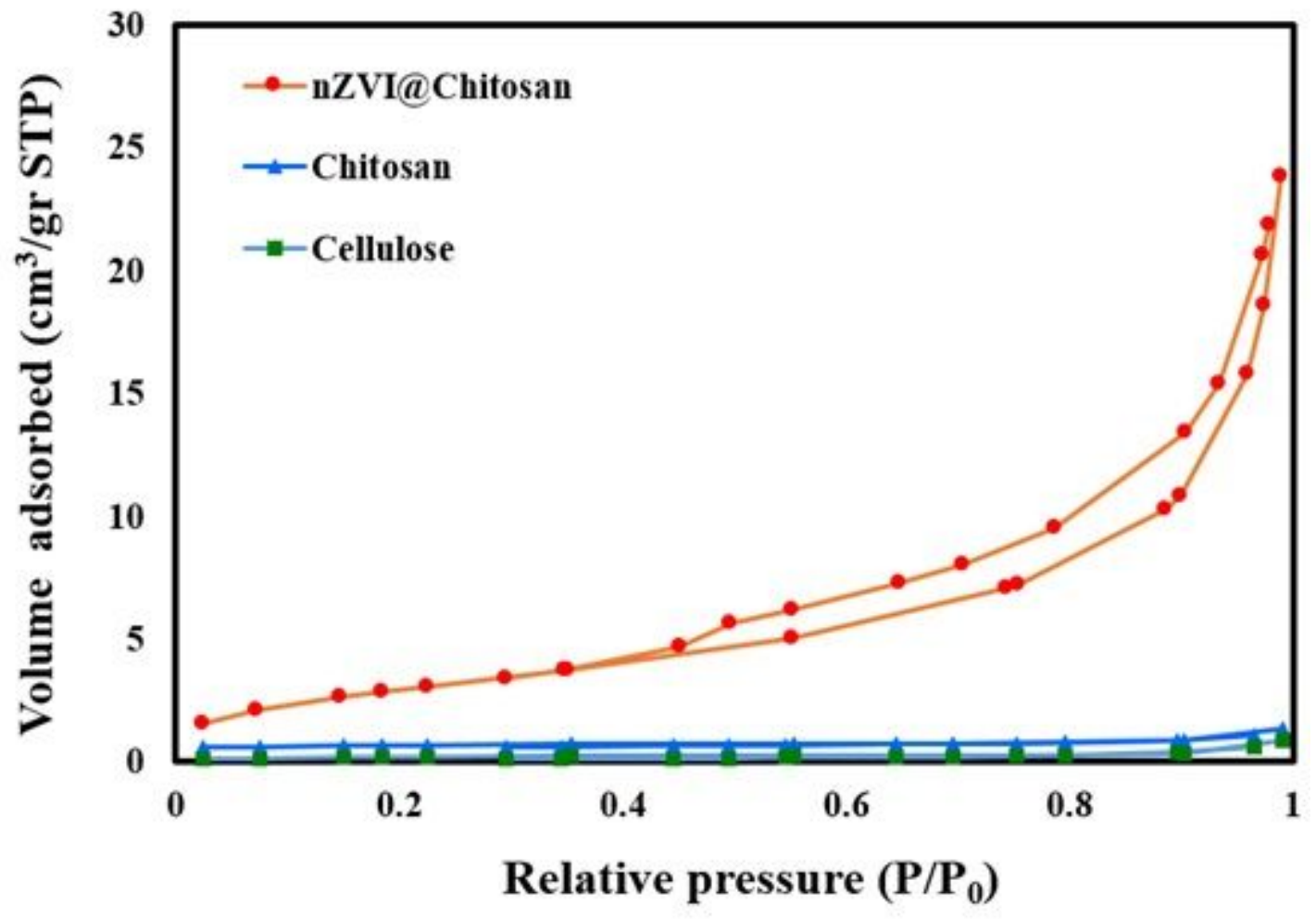


Figure 2

$\mathrm{N} 2$ adsorption and desorption isotherm of cellulose, chitosan and $\mathrm{nZVI} /$ chitosan.

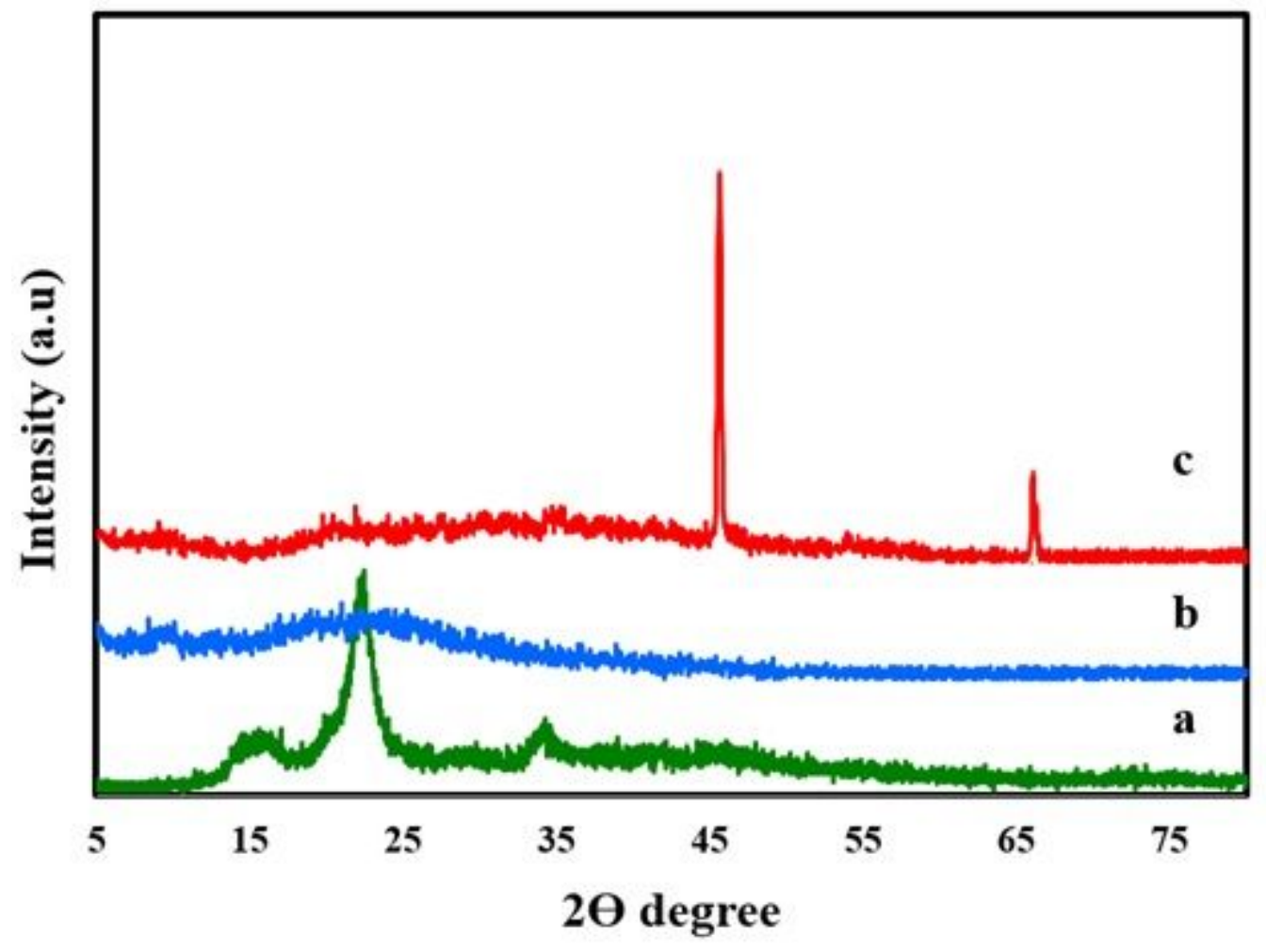

Figure 3

XRD patterns for cellulose (a), chitosan (b) and nZVl/chitosan (c). 

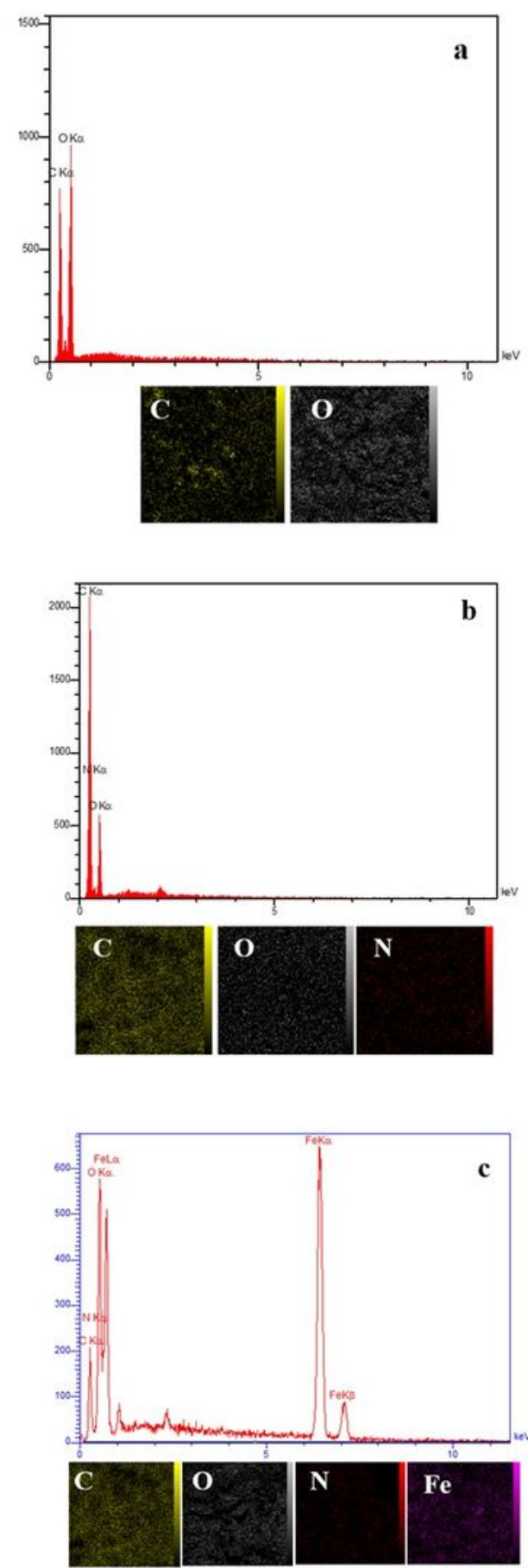

Figure 4

EDX with mapping analysis of cellulose (a), chitosan (b) and nZVI/chitosan (c). 


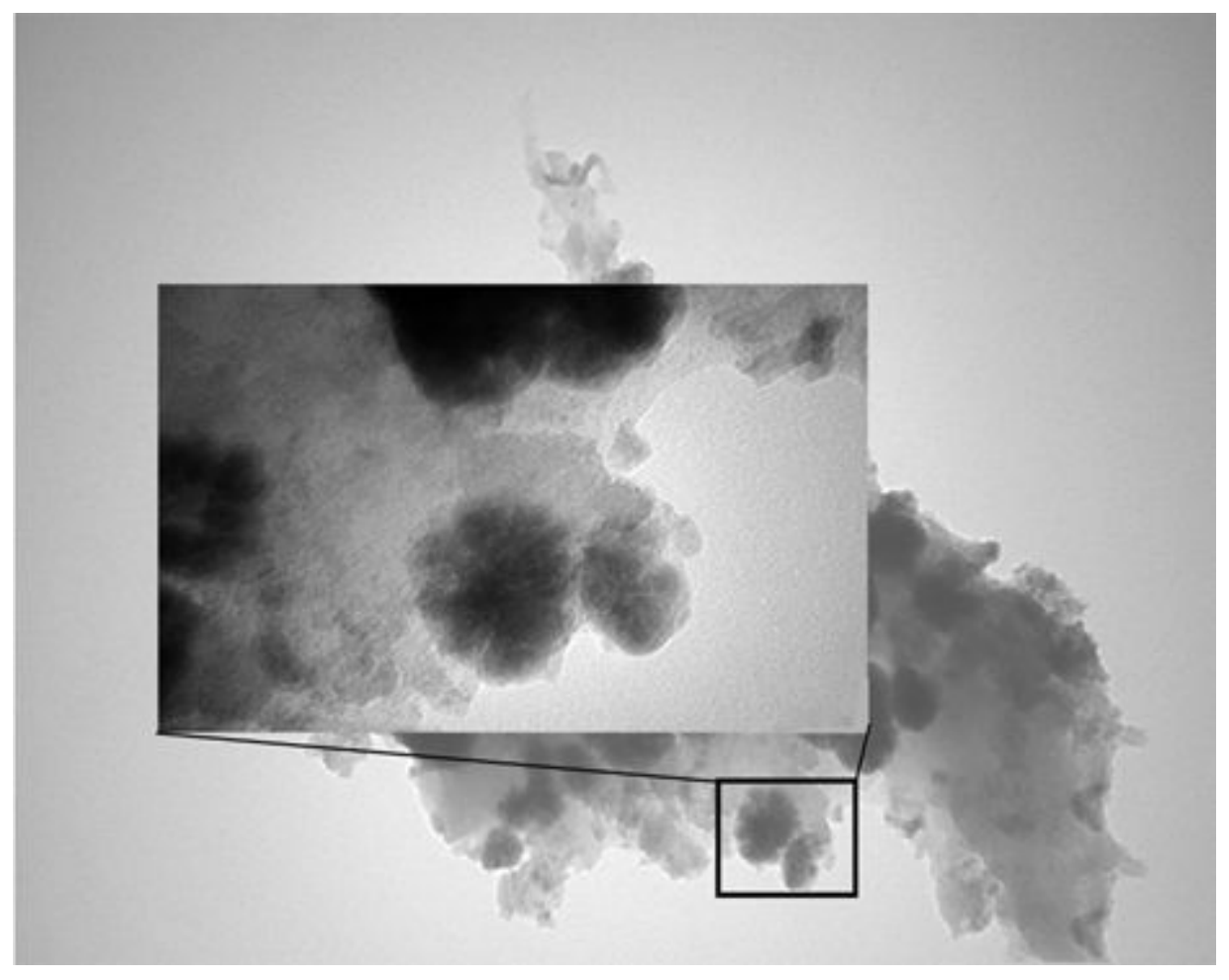

\section{Figure 5}

TEM of $\mathrm{nZVI/chitosan.}$

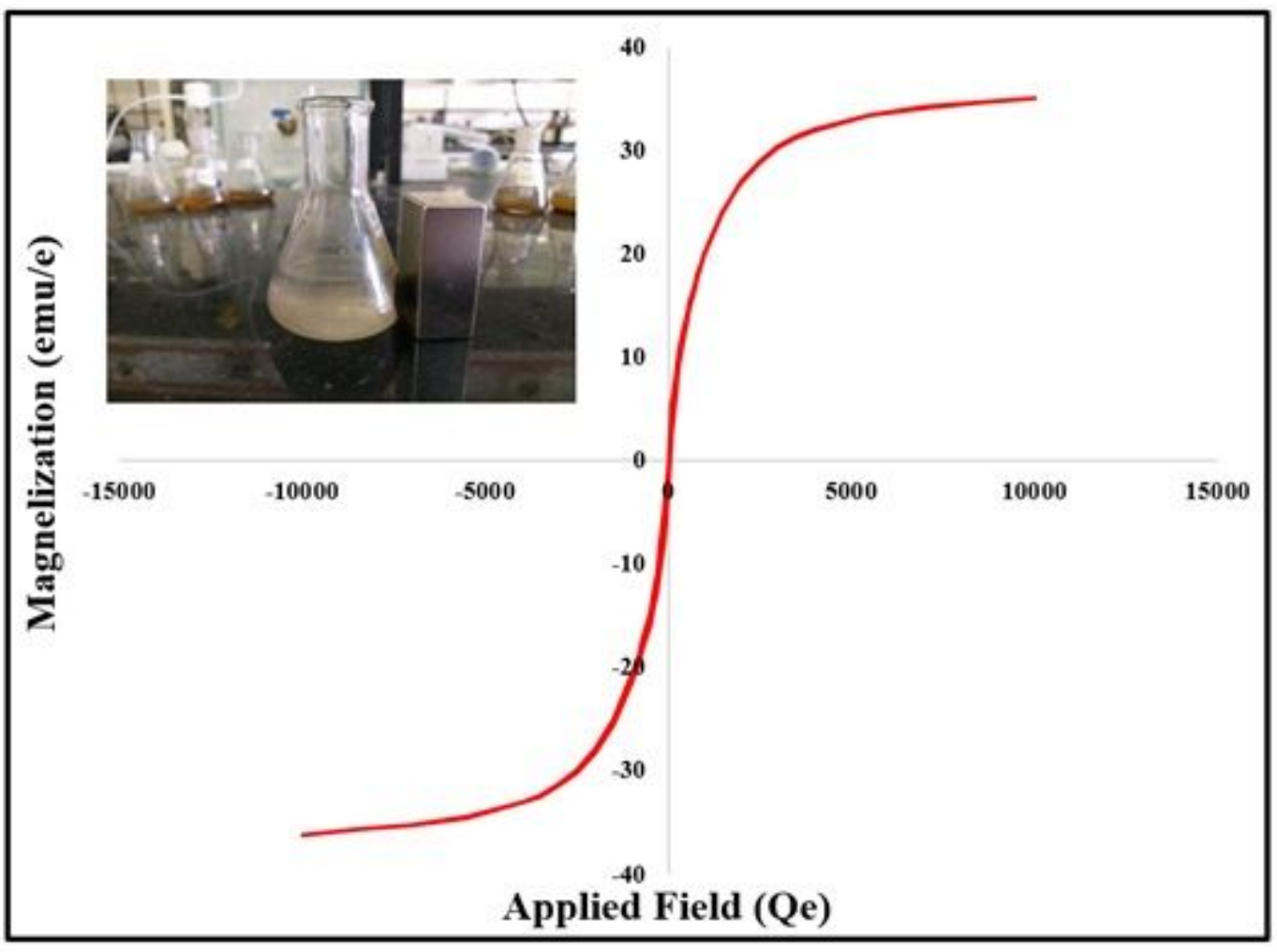

Figure 6

Hysteresis loop of nZVI/chitosan. 


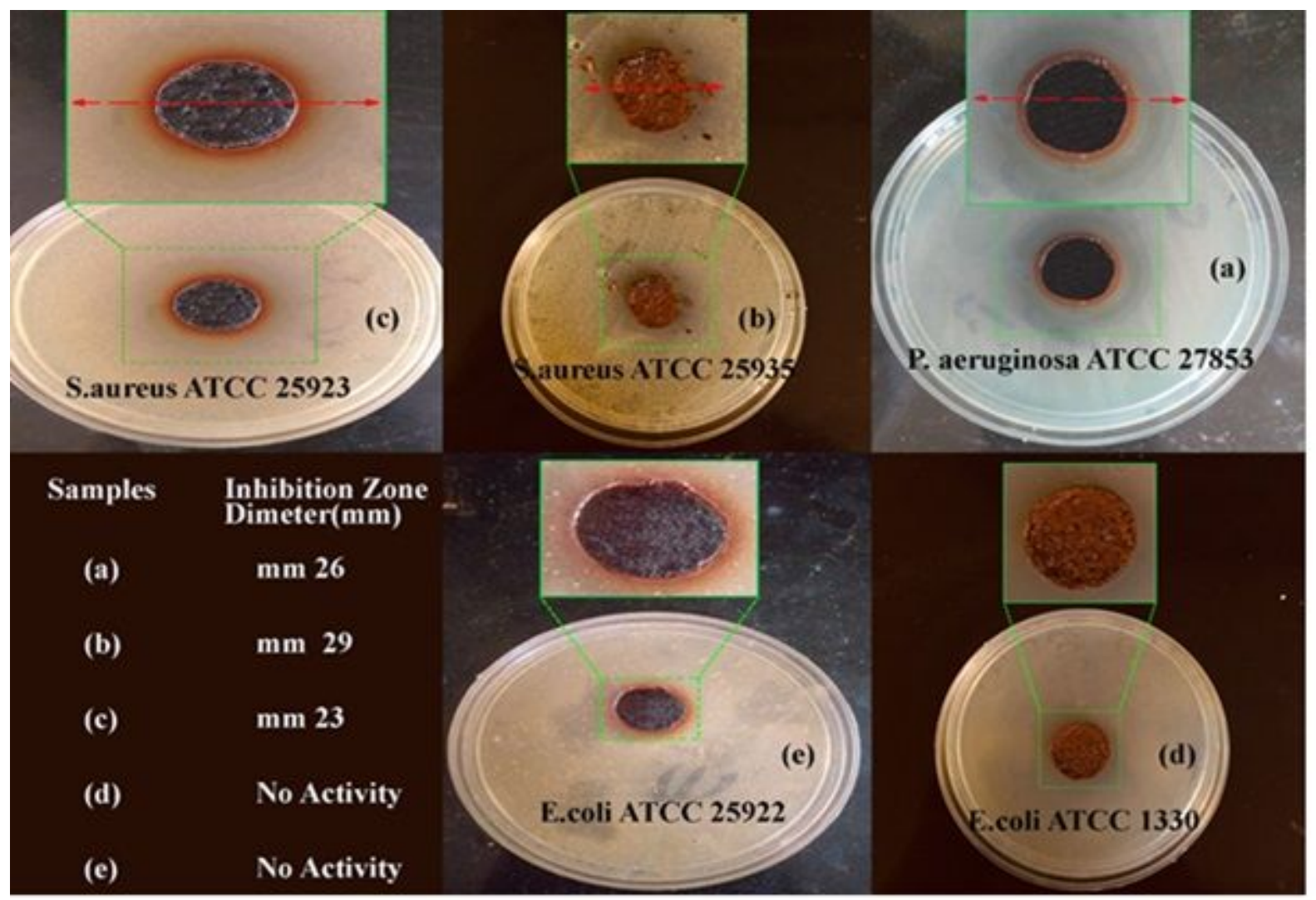

Figure 7

Antibacterial activities of $\mathrm{nZVl} /$ chitosan.

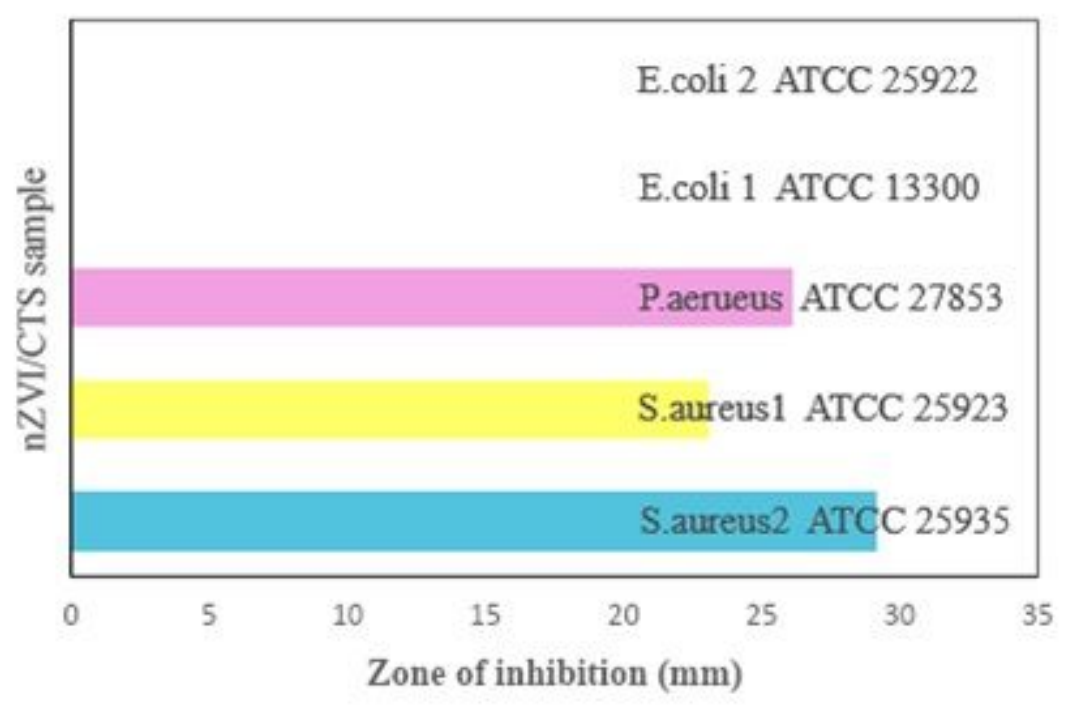

Figure 8

Diameter values of inhibition for $\mathrm{nZVl} /$ chitosan against pathogenic bacteria. 


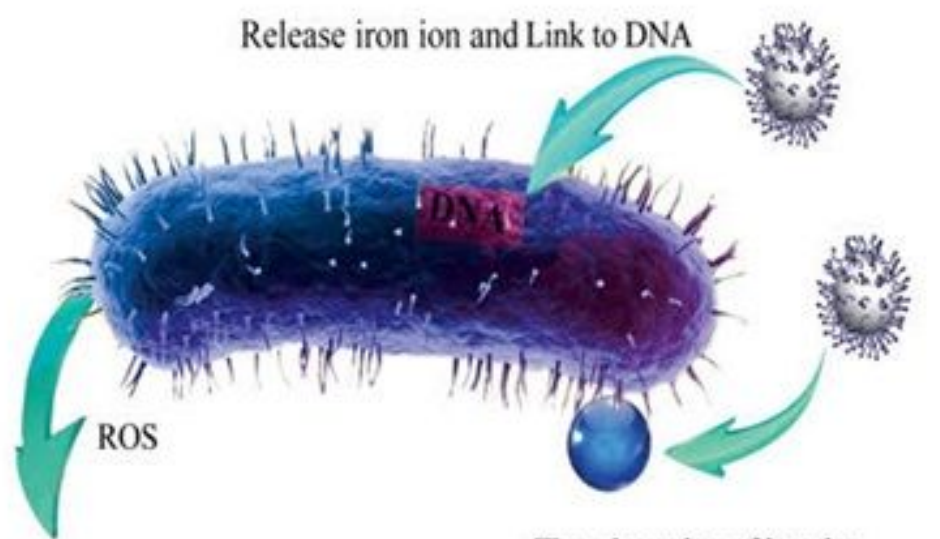

The adsorption of iron ion

$\mathrm{Fe}^{2+}+\mathrm{H}_{2} \mathrm{O}_{2} \longrightarrow \mathrm{Fe}^{\mathrm{s}}+\mathrm{OH}^{*}+\mathrm{OH}^{-} \quad$ by electronegative macromolecules

\section{$\mathrm{nZVI} / \mathrm{CTS}$}

Electronegative macromolecules

\section{Figure 9}

The possible mechanism antibacterial of $\mathrm{nZVI} /$ chitosan.

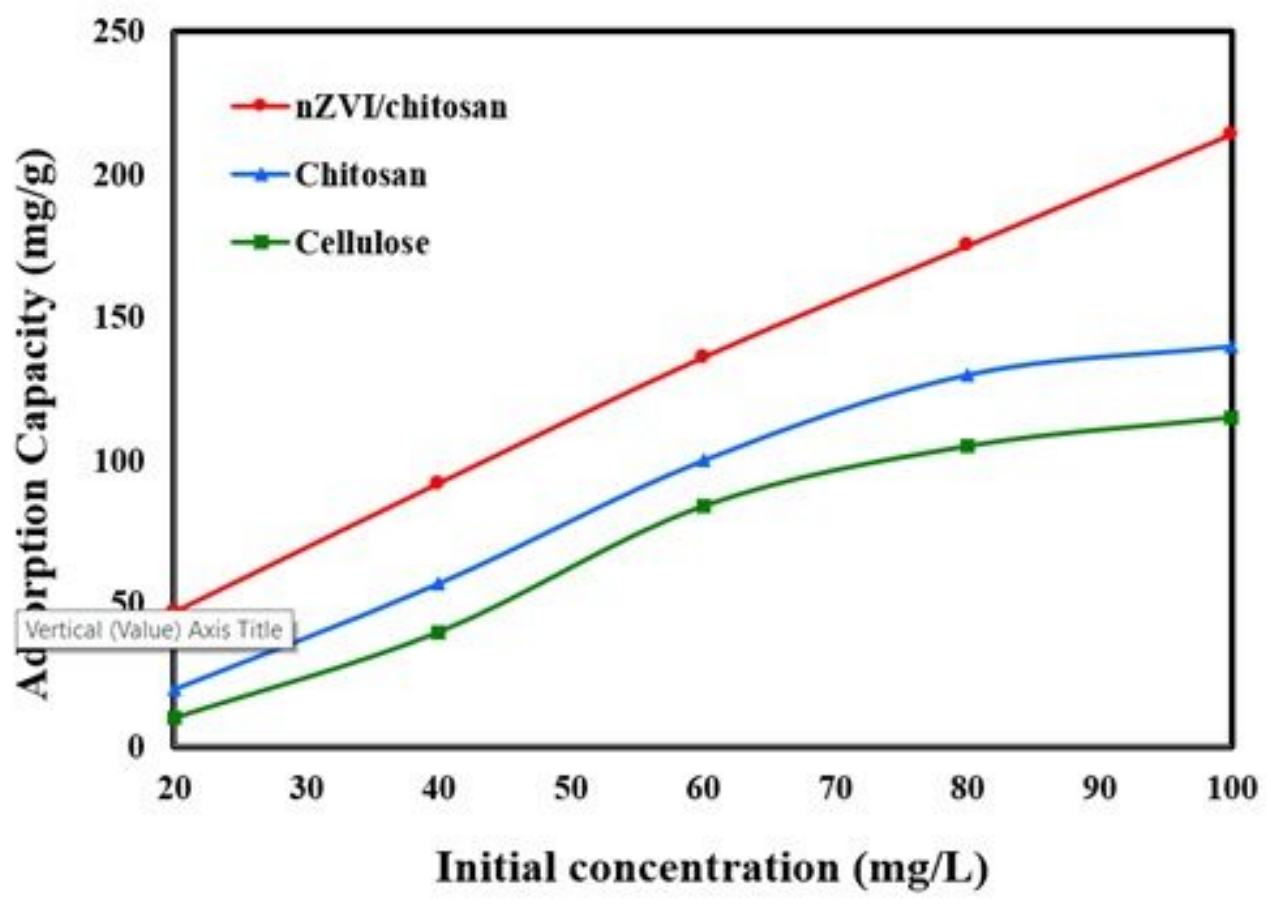

Figure 10

$\mathrm{HA}$ uptakes onto cellulose, chitosan and $\mathrm{nZVl} /$ chitosan $(\mathrm{pH}=5.5, \mathrm{~T}=$ room temperature, $\mathrm{t}=27 \mathrm{~min}$, composite dose $=0.01 \mathrm{mg} / \mathrm{L}$ ). 

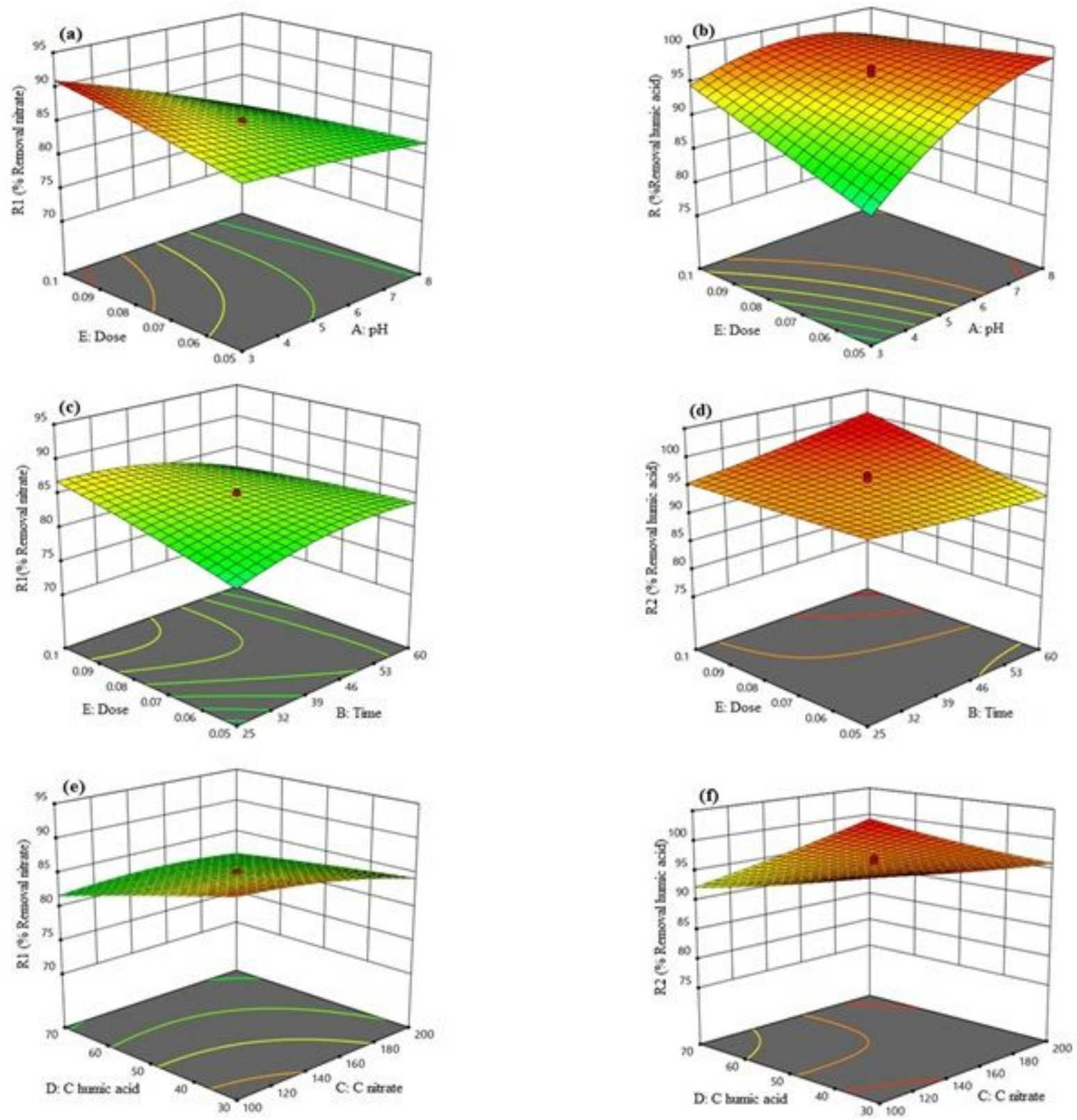

Figure 11

Response surface plots for nitrate and HA adsorption onto $\mathrm{nZVI} /$ chitosan (composite dose and $\mathrm{pH}$ (a and b), contact time and composite dose (c and d) and nitrate concentration and HA concentration (e and f)). 


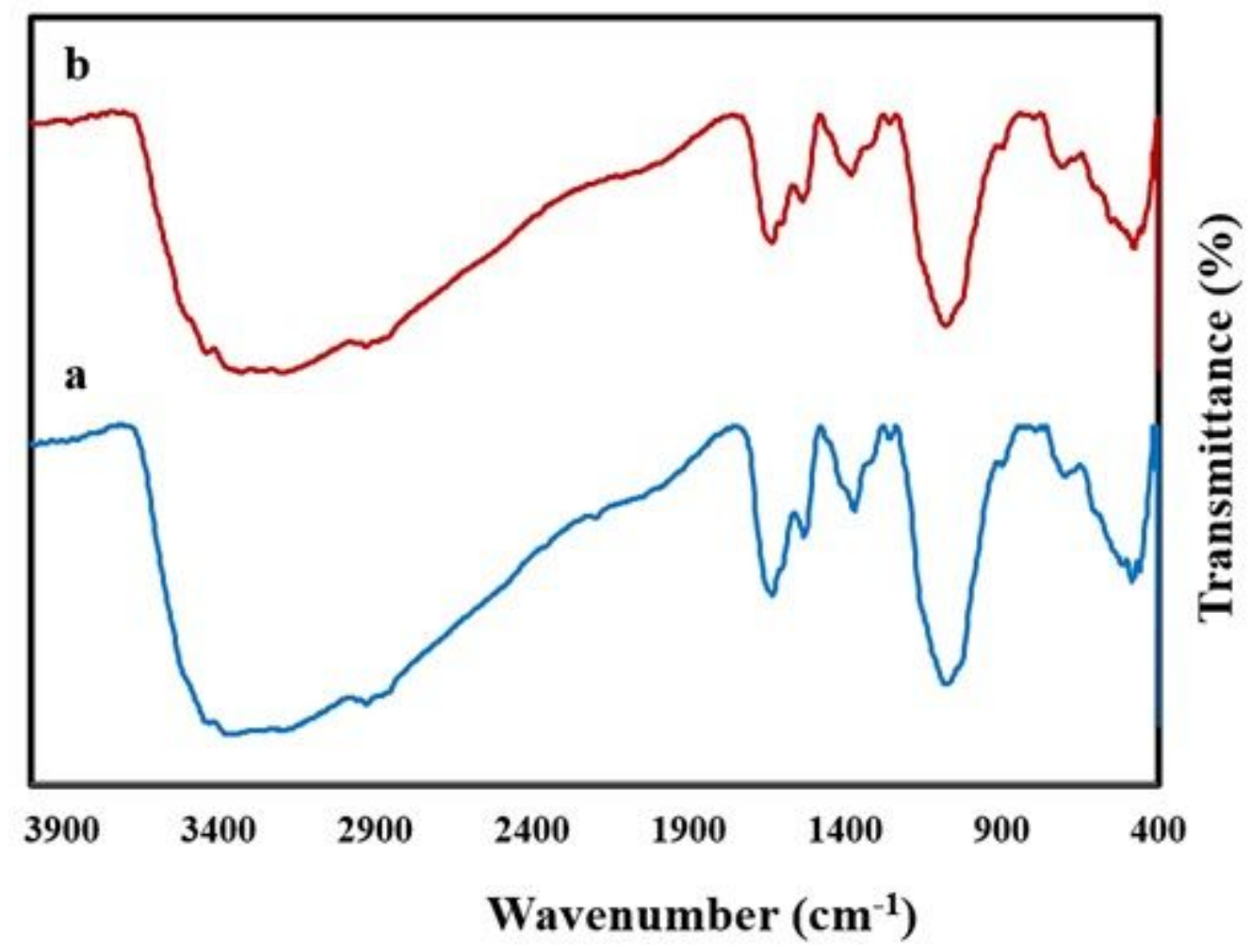

Figure 12

FT-IR spectrums of nZVI/chitosan after reaction with $\mathrm{HA}(\mathrm{a})$ and the HA/nitrate (b) binary system at acidic conditions.

\section{Supplementary Files}

This is a list of supplementary files associated with this preprint. Click to download.

- GraphicalAbstract.jpg 